\title{
Effect of Lipids and Thermal Processing on Antioxidant Activities of Tested Antioxidants and Tom-Kha Paste Extract
}

\author{
Naiyana Pengseng ${ }^{1}$, Sunisa Siripongvutikorn ${ }^{1 *}$, Worapong Usawakesmanee ${ }^{1}$, \\ Saowakon Wattanachant ${ }^{1}$, Pornpong Sutthirak ${ }^{2}$ \\ ${ }^{1}$ Department of Food Technology, Faculty of Agro-Industry, Prince of Songkla University, Hat Yai, Songkhla, Thailand; ${ }^{2}$ Faculty of \\ Science and Industrial Technology, Surat Thani Campus, Prince of Songkla University, Surat Thani, Songkhla, Thailand. \\ Email: ${ }^{*}$ sunisa.s@psu.ac.th, sunisasiripongvutikorn@gmail.com
}

Received February $22^{\text {nd }}, 2013$; revised April $22^{\text {nd }}, 2013$; accepted May $1^{\text {st }}, 2013$

Copyright (C) 2013 Naiyana Pengseng et al. This is an open access article distributed under the Creative Commons Attribution License, which permits unrestricted use, distribution, and reproduction in any medium, provided the original work is properly cited.

\begin{abstract}
The effect of lipids on antioxidant activities of tested antioxidants and Tom-Kha paste extract was determined in the food system. 2,2'-diphenyl-1-picrylhydrazyl (DPPH), 2,2'-azino-bis (3-ethylbenzothiazoline-6-sulfonic acid) diammonium salt (ABTS) scavenging activity, peroxide value (PV), thiobarbituric acid reactive substances (TBARS) and $p$-anisidine value (AV) were methods for determining. The result showed that heating at $121^{\circ} \mathrm{C}$ for 15 min caused decreasing on DPPH scavenging activity of lauric acid but didn't affect ABTS scavenging activity of both lauric acid and virgin coconut oil. DPPH scavenging activity of all mixtures was significantly decreased $(p<0.05)$ after thermal processing. ABTS scavenging activity of the mixtures lauric acid and antioxidants was decreased at ratios 2:1 and 5:1 while at ratios as 10:1 and 15:1 were not changed after heating. Additionally, ABTS scavenging activity in systems of virgin coconut oil mixed with gallic acid and Trolox was decreased after heating. Surprising ABTS scavenging activity of $p$-hydroxycinnamic acid and Tom-Kha paste extract in both lauric acid and virgin coconut oil systems increased after thermal processing. In food systems of lauric acid, PV of almost mixtures except lauric acid-Tom-Kha paste extract 2:1 and lauric acid-Trolox 15:1 was increased after heating. TBARS value of the mixtures was not significantly different $(\mathrm{p}$ $\geq 0.05)$ after thermal processing. AV of only lauric acid-gallic was enhanced after heating. PV of virgin coconut oil added with all tested antioxidant was not changed after heating. TBARS of virgin coconut oil added with antioxidant samples seemed to slightly increase after heating. AV of virgin coconut oil with added gallic acid and Tom-Kha paste extract were not changed by heat treatment while AV of virgin coconut oil with added $p$-hydroxycinnamic acid and Trolox seemed to decrease after heating.
\end{abstract}

Keywords: Lipid Oxidation; Galangal; Tom-Kla; Coconut Oil

\section{Introduction}

Many factors such as light, metal ions, oxygen, temperature and enzymes influence the oxidative stability of lipid-containing food [1]. The lipid oxidation process mainly involves the oxidation of unsaturated fatty acids or their derivatives [2]. The degradation process has been generally established to be a free radical mechanism, yielding primary oxidation products, which in turn degrade to yield secondary oxidation products (e.g., aldehydes, ketones, lactones, alcohols and acids) and this is often associated by the unwanted flavor which is broadly

\footnotetext{
"Corresponding author.
}

described as rancidity [3]. Tom-Kha or galangal coconut milk soup has been classified as the sixth order of top ten Thai cuisines due to its mild taste, sweet and sour flavor [4]. In general, the ingredient of Tom-Kha soup consists of herbs and spices such as galangal rhizome, lemon grass, kaffir lime leaves and chili have been reported as natural antimicrobial agents [5,6] and antioxidants [7-11]. Cooking procedure a coconut milk about $50 \%$ of soup is recommended to add [8]. However, the ratio and/or kind of the ingredients as well as coconut milk used in recipe may differ from home to home or region to region [5] that may also alter consumer preference and antioxidant activity. 
Coconut oil is commercially derived from dried kernel or "meat" of coconut (Cocos nucifera L.) contains a high level of medium chain fatty acids (MCFAs). These MCFAs are similar to that of human milk and have corresponding nutraceutical benefits. The most predominant MCFAs are lauric acid $(45 \%$ - 53\%) [12]. The chemical composition of coconut oil makes it possible to use in a wide range of edible and non-edible purposes. Coconut oil has unique characteristics such as having bland flavor, pleasant odor, high resistance to rancidity, a narrow temperature range of melting, easy digestibility and absorbability, high gross for spray oil use and superior foam retention capacity for whip-topping use [13].

To improve eating quality and safety of food products, and to extend the shelf life of the products, thermal processing is one of the most important processes in the food industry and widely used [13]. On the other hand, thermal processing can promote lipid oxidation by disrupting cell membranes and releasing prooxidants which rapidly developed in food during cooking and storage [3]. Some studies have been showed that cooking methods had negative affected the contents of nutrient and healthpromoting compounds such as vitamin $\mathrm{C}$, carotenoids and polyphenols as well as natural bioactive compounds [14]. However, recent studies showed that thermally processed foods, especially fruits and vegetables, have higher biological activities [15-18]. Four possibilities are suggested for the increase in antioxidant activity of some vegetables after cooking: 1) the liberation of high amounts of antioxidant components due to the thermal destruction of cell walls and subcellular compartments 2) the production of stronger radical-scavenging antioxidants product by thermal chemical reaction 3) increasing of the oxidation capacity of antioxidants by thermal inactivation of oxidative enzymes, and 4) production of new non-nutrient antioxidants or the formation of novel compounds such as Maillard reaction products with antioxidant activity [19].

It is well-known that the antioxidant activity of herbs/ spices may be influenced by many factors such as heat treatment, extraction process or even assay used etc. Moreover, the information of combined effect of lipid and thermal processing in model food system on the antioxidant activity is limited. Therefore, the objective of this study was to investigate the effect of lipid and thermal processing on antioxidant activity of Tom-Kha.

\section{Materials and Methods}

\subsection{Materials}

Fresh galangal rhizomes (Alpinia galanga Swart.), lemon grass (Cymbopogon citratus Stapf.), kaffir lime leaves (Citrus hystrix DC4.) and chili (Capsicum frutescens
Linn.) were purchased from fresh market in Hat-Yai city, Songkhla, Thailand.

\subsection{Chemical and Reagents}

6-Hydroxy-2,5,7,8 tetramethylchroman-2-carboxylic acid (Trolox), 2,2'-azino-bis(3-ethylbenzthiazoline-6-sulphonic acid) diammonium salt (ABTS), 2,2'-diphenyl-1-picrylhydrazyl (DPPH), gallic acid, $p$-hydroxycinnamic acid, $p$-anisidine and thiobarbituric acid (TBA) were purchased from Fluka, Sigma-Aldrich Chemie GmbH Erba (St. Louis, USA). Absolute ethanol and hydrochloric acid were purchased from Merck (Darmstadt, Germany), Potassium persulfate, potassium iodide and sodium thiosulfate were products of Ajax Finechem (New Zealand). Glacial acetic acid and hexane were purchased from LAB-SCAN Erba (Labscan Asia Co., Ltd., 24 Rama, Road, Patumwan, Bangkok 10330 Thailand). Chloroform was purchased from BDH, England. Trichloroacetic (TCA) was purchased from Carlo Erba (Carlo Erba. Reagenti, Milan, Italy).

\subsection{Methods}

\subsubsection{Material Preparation}

Fresh samples were sorted, trimmed, washed, drained for 2 minutes, cut into small pieces and blended until its became a fine paste as $60-20$ mesh. Tom-Kha paste was made by weighing all of cleaned and cut herbs/spices according to recipe composed of galangal, lemon grass, kaffir lime leaves and chili as $41 \%, 47 \%, 3 \%$ and $9 \%$, respectively [16] before brought to blend until it became a fine paste as $60-20$ mesh.

\subsubsection{Extraction Procedure}

One $\mathrm{g}$ of the blended Tom-Kha paste was soaked in $75 \%$ ethanol for 4 days before subjected to filter through cheesecloth followed by filter paper (Whatman No. 1). The filtrate was pooled and dried by a rotary evaporator $(\mathrm{Bu}-$ chi rotavapor, Switzerland) at $40^{\circ} \mathrm{C}-45^{\circ} \mathrm{C}$ to obtain volume approximately $2 \mathrm{ml}$ then adjust final volume as $2 \mathrm{ml}$. The sample was kept in a dark glass bottle and stored at $-20^{\circ} \mathrm{C}$ until used.

\subsubsection{Preparation of Tested Antioxidants}

Gallic acid, Trolox and $p$-hydroxycinnamic acid were separately dissolved in absolute ethanol and diluted to obtain the final concentration as $50 \mu \mathrm{M}, 250 \mu \mathrm{M}$ and 2000 $\mu \mathrm{M}$, respectively.

\subsubsection{Heat Treatment}

Virgin coconut oil (A-tiss D-life, Thailand) and lauric acid (Kosher, Sigma-Aldrich Co., USA) represented as lipid sample were sonicated at $50^{\circ} \mathrm{C}$ for $60 \mathrm{~min}$ with 
sonicater (RK $100 \mathrm{H}$, Bandelin SONOREX, Germany) to initiate lipid oxidation. Sonicated samples were mixed with each antioxidant (gallic acid, $p$-hydroxycinnamic acid, Trolox and Tom-Kha paste extract) as the ratios of $2: 1,5: 1,10: 1$, and 15:1 (v/v) using vortex and sonicated at $50^{\circ} \mathrm{C}$ for $15 \mathrm{~min}$. The samples were heated at $121^{\circ} \mathrm{C}$ for 15 min using autoclave (SS352, Tomy Seiko Co., Ltd., Japan).

\subsection{Determination of Antioxidant Activities}

\subsubsection{DPPH Scavenging Activity}

DPPH scavenging activity was determined by the method of Yen et al., [20] with some modifications. Briefly, a 1.5 $\mathrm{ml}$ of each sample was mixed with $1.5 \mathrm{ml}$ of $0.3 \mathrm{mM}$ DPPH dissolved in absolute ethanol. The mixture was shaken vigorously and left at ambient temperature for 30 min in the dark. The DPPH scavenging activity was determined by measuring the absorbance at $517 \mathrm{~nm}$ using a UV-Visible spectrophotometer (UV-16001, Shimadzu, Kyoto, Japan). Trolox, $p$-hydroxycinnamic acid and gallic acid were used as antioxidant standard and results were reported as $\mu$ mole Trolox equivalent (TE) $/ \mathrm{g}, \mu$ mole $p$-hydroxycinnamic acid equivalent (HCE)/g and $\mu$ mole gallic acid equivalent (GE)/g dried weight (dw) of sample.

\subsubsection{ABTS Scavenging Activity}

The procedure of ABTS scavenging activity followed the method of Pellegrini et al., [21] has been used with minor modifications. $\mathrm{ABTS}^{\circ+}$ radical cation was produced by mixing of $7.4 \mathrm{mM}$ aqueous ABTS and $2.6 \mathrm{mM}$ potassium persulfate then mixture was kept in the dark area at ambient temperature for $12 \mathrm{~h}$. Blue-green $\mathrm{ABTS}^{\text {*+ }}$ was formed at the end of this period. Then the solution was diluted with $50 \mathrm{ml}$ of absolute ethanol before subjected to measure an absorbance of $1.1 \pm 0.02$ units at $734 \mathrm{~nm}$. The sample $(0.15 \mathrm{ml})$ was allowed to react with $2.85 \mathrm{ml}$ of the $\mathrm{ABTS}^{\circ+}$ solution for $2 \mathrm{~h}$ in a dark condition. Then the absorbance was taken at $734 \mathrm{~nm}$ using the UV-Visible spectrophotometer (UV-16001, Shimadzu, Kyoto, Japan). Results are expressed as $\mu$ mole Trolox equivalent (TE) $\mathrm{g}^{-1}, \mu$ mole $p$-hydroxycinnamic acid equivalent (HCE) $\mathrm{g}^{-1}$ and $\mu$ mole gallic acid equivalent (GE) $\mathrm{g}^{-1}$ dried weight $(\mathrm{dw})$ of sample.

\subsection{Peroxide Value (PV)}

The formation of primary products of lipid oxidation (peroxides) was evaluated on an aliquot of the fat extract according to Paquot, [22]. The sample (2 to $5 \mathrm{~g}$ ) was dissolved in $25 \mathrm{ml}$ chloroform-acetic acid mixture $(2: 3, \mathrm{v} / \mathrm{v})$, treated with $1 \mathrm{ml}$ of saturated potassium iodide (KI) solution, and kept in the dark for $5 \mathrm{~min}$. The mixture was treated with $30 \mathrm{ml}$ of distilled water and shaken. One $\mathrm{ml}$ of starch solution $\left(1 \mathrm{~g} \cdot \mathrm{ml}^{-1}, \mathrm{w} / \mathrm{v}\right)$ was added as an indicator. The peroxide value was determined by titrating iodine liberated from potassium iodide with sodium thiosulphate solution. The PV was defined as the reactive oxygen content, expressed as milliequivalents of active oxygen per $\mathrm{kg}$ of lipid (meq $\left.\cdot \mathrm{kg}^{-1}\right)$.

\subsection{Thiobarbituric Acid Reactive Substances (TBARS)}

Thiobarbituric acid reactive substances were determined as described by Buege and Aust, [23]. One milliliter of sample was dispersed in $4 \mathrm{ml}$ of thiobarbituric acid solution $(0.375 \%$ thiobarbituric acid, $15 \%$ trichloroacetic acid and $0.25 \mathrm{~N} \mathrm{HCl}$ ). The mixture was heated in boiling water for $10 \mathrm{~min}$, followed by cooling in running tap water. The mixture was centrifuged at $3600 \times \mathrm{g}$ for $20 \mathrm{~min}$ at room temperature using a centrifuge (Hermle Z323, Hermel Labortechnik, Germany). The absorbance of the supernatant was measured at $532 \mathrm{~nm}$. The standard curve was prepared by using malondialdehyde bis (dimethyl acetal) (MDA) at concentrations ranging from 0 to $10 \mu \mathrm{g}$ $\mathrm{ml}^{-1}$. TBARS value in each sample was expressed as $\mathrm{mg}$ MDA g ${ }^{-1}$ of lipid.

\section{7. p-Anisidine Value (AV)}

The sample $(0.5-4.0 \mathrm{~g})$ was dissolved in $25 \mathrm{ml}$ of hexane and measured at $350 \mathrm{~nm}$. This solution $(5 \mathrm{ml})$ was mixed with $1 \mathrm{ml}$ of $p$-anisidine reagent $\left(2.5 \mathrm{~g} \cdot \mathrm{l}^{-1}\right.$ of $p$ anisidine in glacial acetic acid) for $10 \mathrm{~min}$. The absorbance was read at $350 \mathrm{~nm}$. The $p$-anisidine value was then calculated [22].

\subsection{Statistical Analyses}

Data were subjected to Analysis of Variance (ANOVA) and mean comparisons were performed using the Duncan's multiple range test (DMRT). Differences between the mean scores from non-heated and heated samples were determined using the $t$-test. Statistical analyses were carried out using the SPSS statistical software version 6 (SPSS, Inc., Chicago, IL).

\section{Results and Discussions}

\subsection{Effect of Thermal Processing on Antioxidant Activities of Lauric Acid, Virgin Coconut Oil, Tested Antioxidants and Tom-Kha Paste Extract}

DPPH and ABTS assays are considered to be mainly method based on a proton abstraction and electron transfer reaction. The differences in the antioxidant capacity in the ABTS and DPPH assays depend mainly on the reac- 
tivity of the free radical and the solubility of the different compounds in the testing solution [24]. Additionally, the ABTS method has the extra flexibility at different $\mathrm{pH}$ levels and ABTS is soluble in both aqueous and organic solvents thus, ABTS is useful in assessing antioxidant activity of samples in different media [25]. Effect of thermal processing on antioxidant activity of lauric acid, virgin coconut oil, test antioxidants and Tom-Kha paste extract determined by DPPH and ABTS assay were showed in Tables $\mathbf{1}$ and $\mathbf{2}$. The results were expressed in $\mu$ mole Trolox equivalent (TE), $\mu$ mole $p$-hydroxycinnamic acid equivalent (HCE) and $\mu$ mole gallic acid equivalent (GE) $\mathrm{g}^{-1}$ dried weight ( $\left.\mathrm{dw}\right)$ of sample, respectively. It was found that DPPH scavenging activity of lauric acid, gallic acid and Trolox were decreased while $p$-hydroxycinnamic acid and Tom-Kha paste extract were not changed after heating at $121^{\circ} \mathrm{C}$ for $15 \mathrm{~min}$ (Tables 1 and 2). In addition, ABTS scavenging activity of gallic acid and Trolox decreased after heating while lauric acid, virgin coconut oil, $p$-hydroxycinnamic acid and Tom-Kha paste extract were not significantly changed after heating $(\mathrm{p} \geq$ 0.05 , Table 2). From this result, gallic acid and Trolox were classified as heat labile antioxidant while $p$-hydroxycinnamic acid and Tom-Kha paste extract were heat stable antioxidant. Decreasing of DPPH and ABTS scavenging activities of gallic acid and Trolox might be occurred by the destruction of phenolic hydroxyl groups from high temperature [26]. This result corresponding with Chen et al., [27] who reported that a decrease of DPPH scavenging activity of gallic acid occurred after heating at $90^{\circ} \mathrm{C}$ for $30 \mathrm{~min}$. Arabshahi et al., [28] reported that heating at $100^{\circ} \mathrm{C}$ for 15 min resulted in a significant decrease $(p<0.05)$ in antioxidant activity in drumstick leaves extract due to degradation of natural antioxidant and formation of novel compounds as prooxidant. Moreover, Murcia et al., [29] found that canned vegetables more pronounced loss of antioxidant activity than frozen vegetables and fresh one. The reduction in antioxidant activity as a result of degradation of phenolic compounds in canning might be caused by the high temperatures used during processing.

However, thermal processing did not have a negative effect on DPPH and ABTS scavenging activity of $p$-hydroxycinnamic acid and Tom-Kha paste extract. This

Table 1. Effect of thermal processing on DPPH scavenging activity of lipids, tested antioxidants and Tom-Kha paste extract.

\begin{tabular}{ccccccc}
\hline \multirow{2}{*}{ Samples } & \multicolumn{2}{c}{ DPPH $\left(\mu\right.$ mole TE $\left.\cdot \mathrm{g}^{-1} \mathrm{dw}\right)$} & \multicolumn{2}{c}{ DPPH $\left(\mu \mathrm{mole} \mathrm{HCE} \cdot \mathrm{g}^{-1} \mathrm{dw}\right)$} & \multicolumn{2}{c}{ DPPH $\left(\mu \mathrm{mole} \mathrm{GE} \cdot \mathrm{g}^{-1} \mathrm{dw}\right)$} \\
\cline { 2 - 7 } & Non-heated & Heated & Non-heated & Heated & Non-heated & Heated \\
\hline LA & $0.03 \pm 0.00^{\mathrm{a}}$ & $0.01 \pm 0.00^{\mathrm{b}}$ & $10.47 \pm 2.70^{\mathrm{a}}$ & $2.94 \pm 0.99^{\mathrm{b}}$ & $0.01 \pm 0.00^{\mathrm{a}}$ & $0.01 \pm 0.00^{\mathrm{b}}$ \\
VCO & $\mathrm{ND}$ & $\mathrm{ND}$ & $\mathrm{ND}$ & $\mathrm{ND}$ & ND & ND \\
GA & $2.6 \times 10^{4} \pm 101.53^{\mathrm{a}}$ & $1.8 \times 10^{4} \pm 382.24^{\mathrm{b}}$ & $1.4 \times 10^{6} \pm 58887.91^{\mathrm{a}}$ & $9.8 \times 10^{6} \pm 221698.45^{\mathrm{b}}$ & $1.2 \times 10^{4} \pm 47.68^{\mathrm{a}}$ & $8.8 \times 10^{3} \pm 179.51^{\mathrm{b}}$ \\
HC & $3.1 \times 10 \pm 0.21^{\mathrm{b}}$ & $3.7 \times 10 \pm 2.93^{\mathrm{a}}$ & $1.7 \times 10^{3} \pm 123.09^{\mathrm{b}}$ & $5.4 \times 10^{3} \pm 1699.75^{\mathrm{a}}$ & $1.4 \times 10 \pm 0.10^{\mathrm{b}}$ & $1.8 \times 10 \pm 1.38^{\mathrm{a}}$ \\
T & $2.2 \times 10^{3} \pm 7.19^{\mathrm{a}}$ & $2.1 \times 10^{3} \pm 61.09^{\mathrm{b}}$ & $1.2 \times 10^{6} \pm 4168.22^{\mathrm{a}}$ & $1.1 \times 10^{6} \pm 35432.86^{\mathrm{b}}$ & $1.0 \times 10^{3} \pm 3.38^{\mathrm{a}}$ & $9.9 \times 10^{2} \pm 28.69^{\mathrm{b}}$ \\
TK & $1.8 \times 10 \pm 0.09^{\mathrm{a}}$ & $1.8 \times 10 \pm 0.32^{\mathrm{a}}$ & $9.7 \times 10^{3} \pm 52.43^{\mathrm{a}}$ & $9.6 \times 10^{3} \pm 186.41^{\mathrm{a}}$ & $8.58 \pm 0.04^{\mathrm{a}}$ & $8.52 \pm 0.15^{\mathrm{a}}$ \\
\hline
\end{tabular}

$\mathrm{LA}=$ lauric acid, $\mathrm{VCO}=$ Virgin coconut oil, $\mathrm{GA}=$ gallic acid, $\mathrm{HC}=p$-Hydroxycinnamic acid, $\mathrm{T}=$ Trolox and $\mathrm{TK}=$ Tom-Kha paste extract; $\mathrm{ND}=$ not deter mined, ${ }^{\mathrm{a}-\mathrm{b}}$ Means within a row and same condition with different letters were significantly different $(\mathrm{p}<0.05)$.

Table 2. Effect of thermal processing on ABTS scavenging activity of lipids, tested antioxidants and Tom-Kha paste extract.

\begin{tabular}{ccccccc}
\hline \multirow{2}{*}{ Samples } & \multicolumn{2}{c}{ ABTS $\left(\mu\right.$ mole TE·g $\left.{ }^{-1} \mathrm{dw}\right)$} & \multicolumn{2}{c}{ ABTS $\left(\mu\right.$ mole HCE $\left.\cdot \mathrm{g}^{-1} \mathrm{dw}\right)$} & \multicolumn{2}{c}{ ABTS $\left(\mu \mathrm{mole} \mathrm{GE} \cdot \mathrm{g}^{-1} \mathrm{dw}\right)$} \\
\cline { 2 - 7 } & Non-heated & Heated & Non-heated & Heated & Non-heated & Heated \\
\hline LA & $0.08 \pm 0.01^{\mathrm{a}}$ & $0.09 \pm 0.01^{\mathrm{a}}$ & $3.06 \pm 0.26^{\mathrm{a}}$ & $3.50 \pm 0.41^{\mathrm{a}}$ & $0.03 \pm 0.00^{\mathrm{a}}$ & $0.03 \pm 0.00^{\mathrm{a}}$ \\
VCO & $0.10 \pm 0.00^{\mathrm{a}}$ & $0.10 \pm 0.00^{\mathrm{a}}$ & $3.74 \pm 0.04^{\mathrm{a}}$ & $3.77 \pm 0.04^{\mathrm{a}}$ & $0.03 \pm 0.00^{\mathrm{a}}$ & $0.03 \pm 0.00^{\mathrm{a}}$ \\
GA & $3.5 \times 10^{4} \pm 163.09^{\mathrm{a}}$ & $1.9 \times 10^{4} \pm 142.59^{\mathrm{b}}$ & $1.6 \times 10^{6} \pm 8,154.50^{\mathrm{a}}$ & $8.4 \times 10^{5} \pm 7129.64^{\mathrm{b}}$ & $1.1 \times 10^{4} \pm 53.18^{\mathrm{a}}$ & $6.2 \times 10^{3} \pm 46.50^{\mathrm{b}}$ \\
HC & $3.7 \times 10^{3} \pm 66.90^{\mathrm{a}}$ & $3.7 \times 10^{3} \pm 338.57^{\mathrm{a}}$ & $1.5 \times 10^{5} \pm 3345.24^{\mathrm{a}}$ & $1.5 \times 10^{5} \pm 16928.48^{\mathrm{a}}$ & $1.2 \times 10^{3} \pm 21.82^{\mathrm{a}}$ & $1.2 \times 10^{3} \pm 110.40^{\mathrm{a}}$ \\
T & $4.8 \times 10^{3} \pm 3.91^{\mathrm{a}}$ & $4.1 \times 10^{3} \pm 12.42^{\mathrm{b}}$ & $2.3 \times 10^{5} \pm 195.30^{\mathrm{a}}$ & $1.8 \times 10^{5} \pm 621.00^{\mathrm{b}}$ & $1.6 \times 10^{3} \pm 1.27^{\mathrm{a}}$ & $1.3 \times 10^{3} \pm 4.05^{\mathrm{b}}$ \\
TK & $9.1 \times 10 \pm 2.10^{\mathrm{a}}$ & $9.4 \times 10 \pm 2.57^{\mathrm{a}}$ & $4.3 \times 10^{3} \pm 104.90^{\mathrm{a}}$ & $4.5 \times 10^{3} \pm 128.53^{\mathrm{a}}$ & $3.0 \times 10 \pm 0.68^{\mathrm{a}}$ & $3.0 \times 10 \pm 0.84^{\mathrm{a}}$ \\
\hline
\end{tabular}

$\mathrm{LA}=$ lauric acid, $\mathrm{VCO}=$ Virgin coconut oil, $\mathrm{GA}=$ gallic acid, $\mathrm{HC}=p$-Hydroxycinnamic acid, $\mathrm{T}=$ Trolox and TK=Tom-Kha paste extract; ${ }^{\mathrm{a}-\mathrm{b}} \mathrm{Means}$ within a row and same condition with different letters were significantly different $(\mathrm{p}<0.05)$. 
result was similar to Ayusuk et al., [16] who reported that Tom-Kha paste extract were heat stable. It was possible that thermal processing could induce the formation of compounds with antioxidant properties $[19,30]$ and prooxidants were inactivated at high temperatures [31]. Moreover, an increase in antioxidant activity of samples may be due to thermal processing which associated with increased levels of free phenolic acids [32] or even the heat resistance compound. Seah et al., [33] who addressed that DPPH scavenging activity and ferric reducing antioxidant power (FRAP) of turmeric-chili paste were increased after heat treatment. Juntachote et al., [34] also reported that antioxidant activity of ethanolic galangal extract was heat stable after heating at $80^{\circ} \mathrm{C}$ for 60 min. Rehman et al., [35] showed that heated ginger extract exhibited $85.2 \%$ inhibition of peroxidation of linoleic acid. Moreover, Xu et al., [36] found that after heat treatment, ABTS scavenging and FRAP activity of the citrus peel extract were increased. It was possible that heat treatment cleaved the esterified bond and glycosylated bond, etc. of polyphenols resulted in the free active compound increased [36,37]. The results from Table 2 showed that virgin coconut oil seemed to have ABTS activity as lauric acid. However, it was found that there was no DPPH activity detected in virgin coconut oil (Table 1) may be due to dissolved problem. Therefore, using each antioxidant activity assay would be considered otherwise fault detection may occur. Heating, $121^{\circ} \mathrm{C}$ for 15 min caused decreasing on DPPH activity of lauric acid but not on ABTS scavenging activity of both lauric acid and virgin coconut oil. This result similarly with Marina et al., [13] who reported that the antioxidant activity of virgin coconut oil samples ranged from 7.78 to $29.18 \mathrm{mg}$ GE. $100 \mathrm{~g}^{-1}$ oil which was higher than antioxidant activity of refined, bleached and deodorized coconut oil (RBDCO). This might be due to total phenolic contents of virgin coconut oil samples (7.78 - 29.18 mg GE. 100 $\mathrm{g}^{-1}$ oil) were significantly $(\mathrm{p}<0.05)$ higher than RBDCO (6.14 mg GE. $100 \mathrm{~g}^{-1}$ oil). However, Seneviratne, et al. [38] reported that the coconut oil extracted under hot conditions $(\mathrm{COEH})$ contained more phenolic substances than the coconut oil extracted under cold conditions (COEC) and the antioxidant potential of $\mathrm{COEH}$ ) was higher than that of COEC) as determined by DPPH assay, deoxyribose assay and in vivo assay of serum antioxidant capacity. Marina et al., [39] also reported that gallic acid, (-)-epigallocatechin and syringic acid were the major phenolic compounds present in VCO while gallic acid (-)-epigallocatechin, (+)-catechin, $p$-hydroxybenzoic acid, $(+)$-epicatechin, caffeic acid, syringic acid and ferulic acid were identified in traditional coconut oil (hot extraction). Moreover, Marina et al., [39] reported that the major phenolic acids in virgin coconut oil were ferulic acid and $p$-hydroxycinnamic acid. It can be stated that the antioxidant activity of materials may differ from type and part of used sample, extraction process, protocol and assay method.

\subsection{Combined Treatment Effect of Lipids and Thermal Processing on Antioxidant Activities of Tested Antioxidants and Tom-Kha Paste Extract}

Combined treatment effect of lauric acid (LA) and thermal processing on DPPH scavenging activity of gallic acid, $p$-hydroxycinnamic acid, Trolox, Tom-Kha paste extract and control (absolute ethanol) as the ratio of 2:1, 5:1, 10:1 and 15:1 expressed in $\mu$ mole TE, $\mu$ mole HCE and $\mu$ mole GE ${ }^{-1}$ of sample were showed in Figures 1-3, respectively. It was found that DPPH scavenging activity of all mixtures were significantly decreased $(p<0.05)$ after thermal processing at $121^{\circ} \mathrm{C}$ for $15 \mathrm{~min}$. Although the previously results showed that thermal processing did not have negative affected on DPPH scavenging activity of $p$-hydroxycinnamic acid and Tom-Kha paste extract. It implied that lauric acid reduced antioxidant activity of all antioxidants and Tom-Kha paste extract may be due to van der waals interaction between fatty acid chains and phenolic compounds [40]. Moreover, thermal processing induced autoxidation of lauric acid [3]. Thereafter thermal processing brought to the destruction of phenolic hydroxyl groups and degradation of phenolic compounds [27-29]. In addition, Yen et al., [41] reported that ascorbic acid and gallic acid at lower concentrations (0.004 $0.24 \mathrm{mM}$ ) would change to be prooxidant when testing with high concentrations of free radical or active oxygen and metal ion. It was explanation by their weak metalchelating effects and their strong electron-donating effects (reducing ability), as well as their stimulation of oxidative effects.

ABTS scavenging activity of mixtures expressed in $\mu$ mole TE, $\mu$ mole $\mathrm{HCE}$ and $\mu$ mole $\mathrm{GEg}^{-1} \mathrm{dw}$ of lauric acid and virgin coconut oil were showed in Figures 4-9. The result showed that ABTS scavenging activity of the mixtures lauric acid and antioxidants (LA:GA and LA:T) was decreased at ratio 2:1 and 5:1 while at ratios as 10:1 and 15:1 were not changed after heating. Additionally, in systems of virgin coconut oil mixed with gallic acid and Trolox were decreased after heating (Figures 7-9). Surprising ABTS scavenging activity of $p$-hydroxycinnamic acid and Tom-Kha paste extract in both lauric acid and virgin coconut oil system increased after thermal processing. This may be due to the solubility of polar phenolic substances such as gallic acid, $p$-hydroxybenzoic acid, caffeic acid, syringic acid and ferulic acid in non-polar coconut oil was certainly improved at high temperatures, then more phenolic substances would be more dissolved 


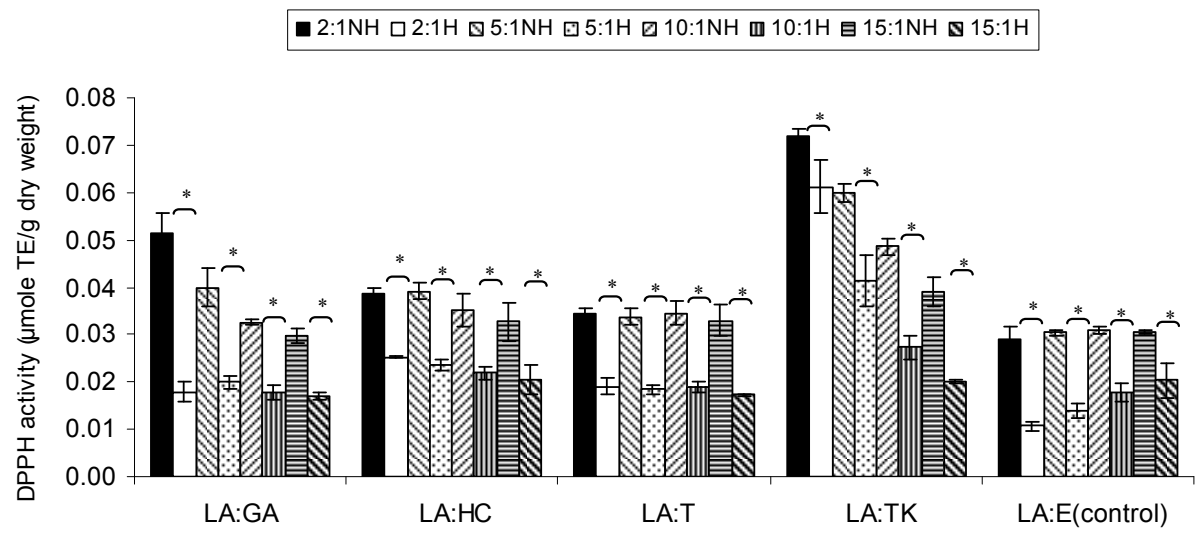

Figure 1. Combined effect of lauric acid (LA) and thermal processing on DPPH scavenging activity of gallic acid (GA), p-hydroxycinnamic acid (HC), Trolox (T), Tom-Kha paste extract (TK) and absolute ethanol (E) expressed in $\mu \mathrm{mole}$ TE $\mathrm{g}^{-1}$ dw. The ratios of LA: antioxidant $=2: 1,5: 1,10: 1$ and 15:1. $\mathrm{NH}=$ no heat treatment, $H=$ heat treatment, $n s=$ not significant, * significant $(\mathbf{p}<0.05)$.

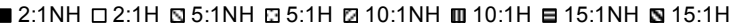

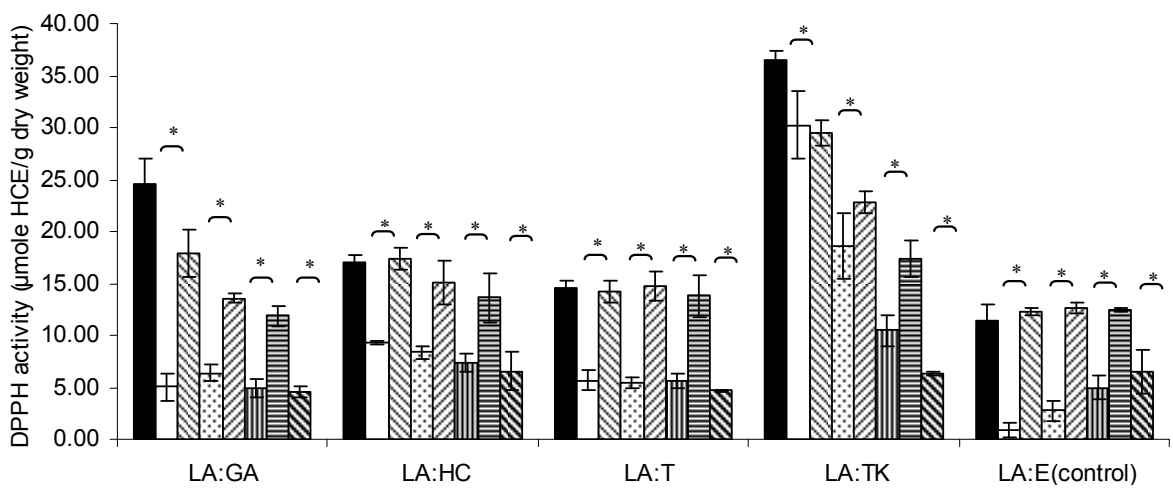

Figure 2. Combined effect of lauric acid (LA) and thermal processing on DPPH scavenging activity of gallic acid (GA), p-hydroxycinnamic acid (HC), Trolox (T), Tom-Kha paste extract (TK) and absolute ethanol (E) expressed in $\mu \mathrm{mole} \mathrm{HCE}^{-1}$ dw. The ratios of LA: antioxidant $=2: 1,5: 1,10: 1$ and 15:1. $\mathrm{NH}=$ no heat treatment, $H=$ heat treatment, $n s=$ not significant, " $=$ significant $(p<0.05)$.

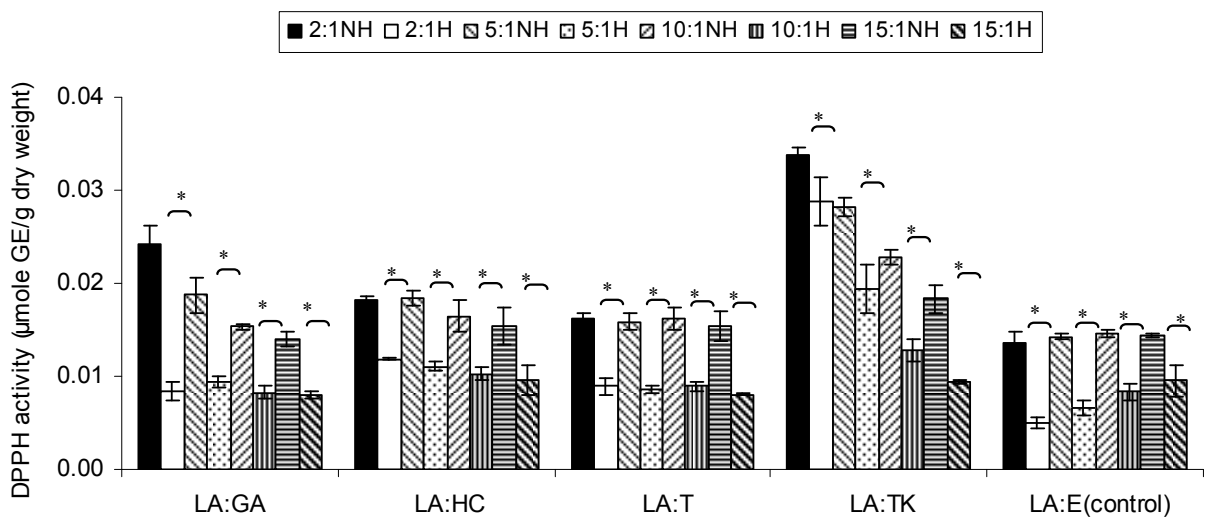

Figure 3. Combined effect of lauric acid (LA) and thermal processing on DPPH scavenging activity of gallic acid (GA), p-hydroxycinnamic acid (HC), Trolox (T), Tom-Kha paste extract (TK) and absolute ethanol (E) expressed in $\mu \mathrm{mole}$ GE $\mathrm{g}^{-1}$ dw. The ratios of LA: antioxidant $=2: 1,5: 1,10: 1$ and 15:1. $\mathrm{NH}=$ no heat treatment, $H=$ heat treatment, ns $=$ not significant, = significant $(\mathbf{p}<0.05)$. 


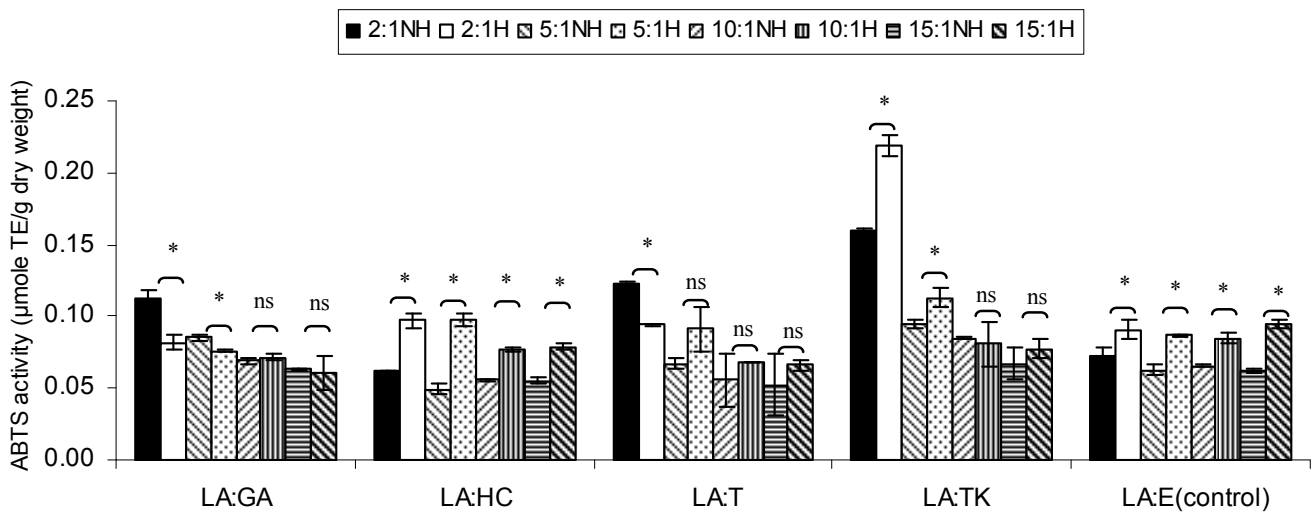

Figure 4. Combined effect of lauric acid (LA) and thermal processing on ABTS scavenging activity of gallic acid (GA), $p$-hydroxycinnamic acid (HC), Trolox (T), Tom-Kha paste extract (TK) and absolute ethanol (E) expressed in $\mu$ mole TE $\mathrm{g}^{-1}$ dw. The ratios of LA: antioxidant $=2: 1,5: 1,10: 1$ and 15:1. $\mathrm{NH}=$ no heat treatment, $H=$ heat treatment, $n s=$ not significant, * = significant $(\mathbf{p}<0.05)$.

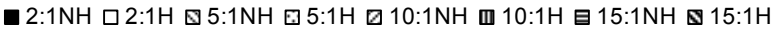

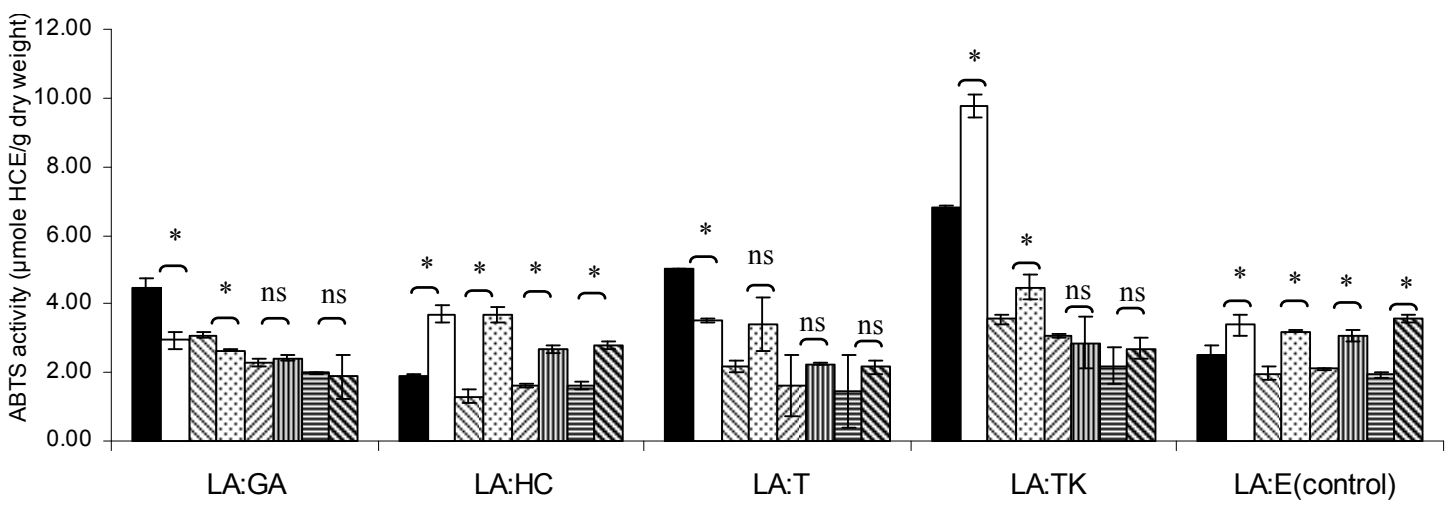

Figure 5. Combined effect of lauric acid (LA) and thermal processing on ABTS scavenging activity of gallic acid (GA), $p$-hydroxycinnamic acid (HC), Trolox (T), Tom-Kha paste extract (TK) and absolute ethanol (E) expressed in $\mu \mathrm{mole}$ HCE $\mathrm{g}^{-1}$ dw. The ratios of $L A$ : antioxidant $=2: 1,5: 1,10: 1$ and 15:1. $\mathrm{NH}=$ no heat treatment, $H=$ heat treatment, $n s=$ not significant, " significant $(\mathrm{p}<0.05)$.

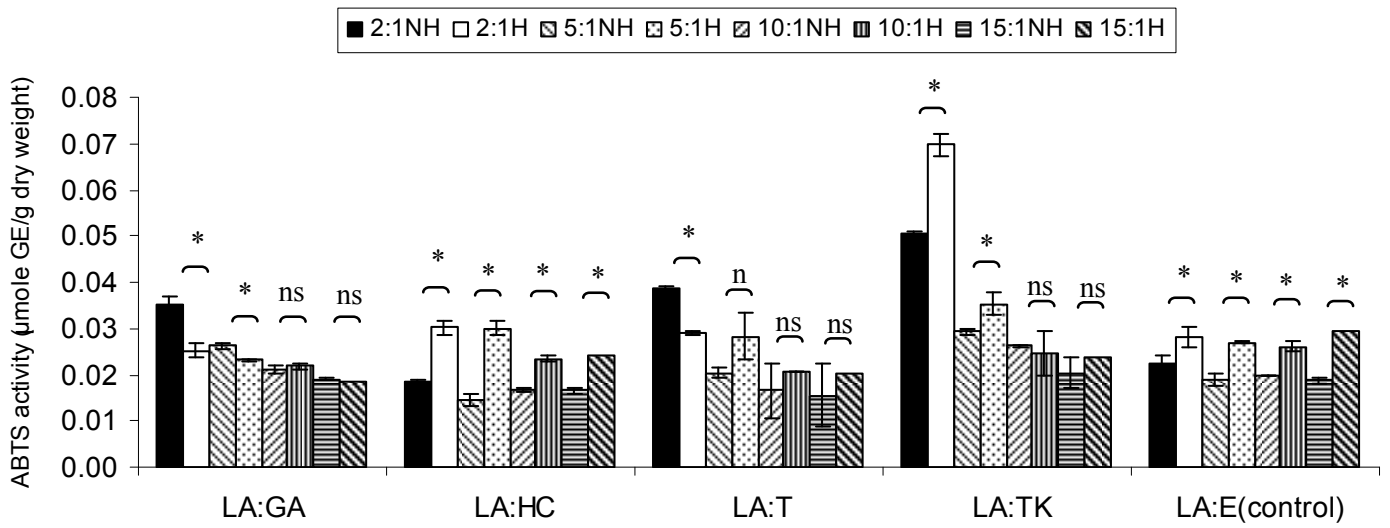

Figure 6. Combined effect of lauric acid (LA) and thermal processing on ABTS scavenging activity of gallic acid (GA), $p$-hydroxycinnamic acid (HC), Trolox (T), Tom-Kha paste extract (TK) and absolute ethanol (E) expressed in $\mu \mathrm{mole}^{\mathrm{GE}} \mathrm{g}^{-1}$ dw. The ratios of LA: antioxidant $=2: 1,5: 1,10: 1$ and 15:1. $\mathrm{NH}=$ no heat treatment, $H=$ heat treatment, $n s=$ not significant, " significant $(\mathbf{p}<0.05)$. 


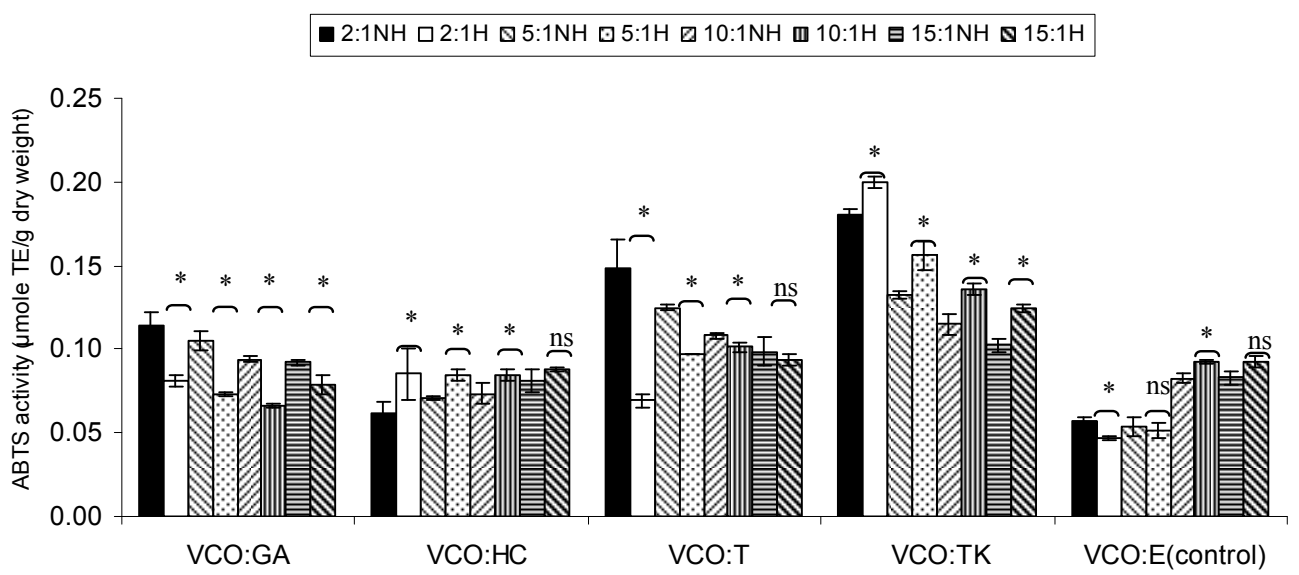

Figure 7. Combined effect of virgin coconut oil (VCO) and thermal processing on ABTS scavenging activity of gallic acid (GA), p-hydroxycinnamic acid (HC), Trolox (T), Tom-Kha paste extract (TK) and absolute ethanol (E) expressed in $\mu \mathrm{mole}$ TE $\mathrm{g}^{-1} \mathrm{dw}$. The ratios of VCO: antioxidant $=2: 1,5: 1,10: 1$ and 15:1. $\mathrm{NH}=$ no heat treatment, $\mathrm{H}=$ heat treatment, ns $=$ not significant, ${ }^{*}=$ significant $(\mathrm{p}<\mathbf{0 . 0 5})$.

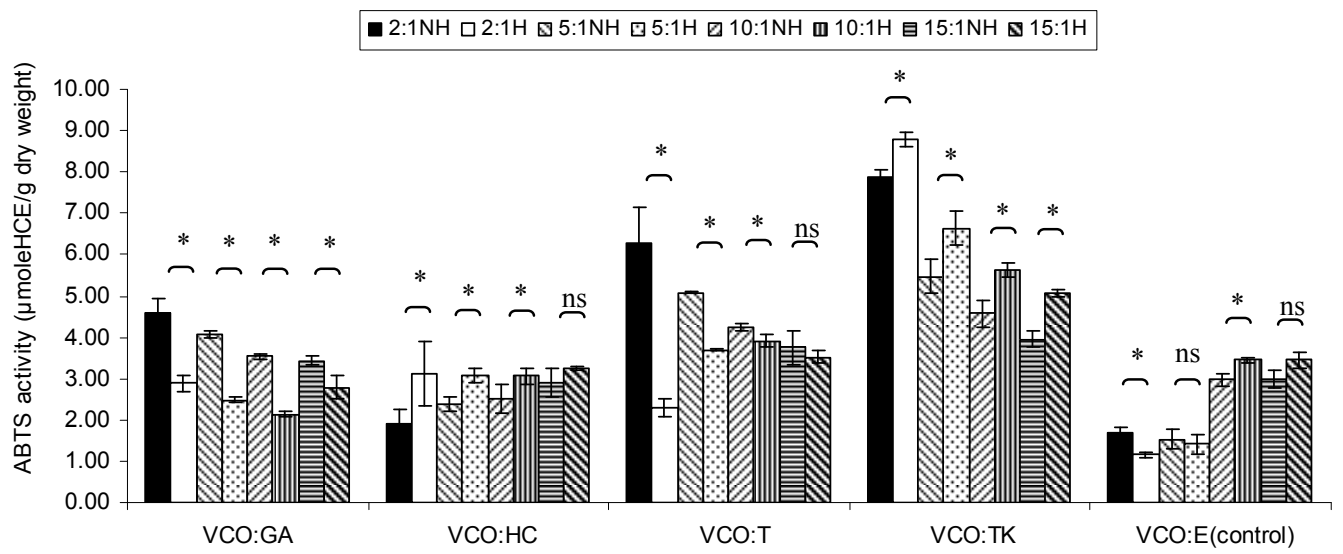

Figure 8. Combined effect of virgin coconut oil (VCO) and thermal processing on ABTS scavenging activity of gallic acid (GA), p-hydroxycinnamic acid (HC), Trolox (T), Tom-Kha paste extract (TK) and absolute ethanol (E) expressed in $\mu \mathrm{mole}$ HCE $\mathrm{g}^{-1}$ dw. The ratios of VCO: antioxidant $=2: 1,5: 1,10: 1$ and 15:1. $\mathrm{NH}=$ no heat treatment, $\mathrm{H}=$ heat treatment, ns $=$ not significant, ${ }^{*}=$ significant $(\mathrm{p}<\mathbf{0 . 0 5})$.

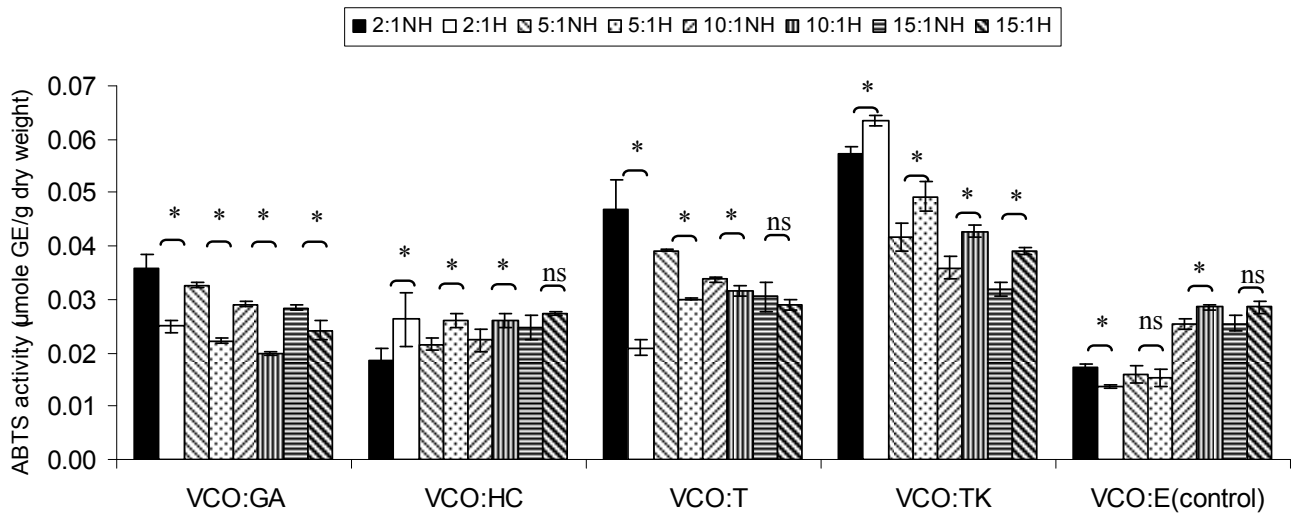

Figure 9. Combined effect of virgin coconut oil (VCO) and thermal processing on ABTS scavenging activity of gallic acid (GA), p-hydroxycinnamic acid (HC), Trolox (T), Tom-Kha paste extract (TK) and absolute ethanol (E) expressed in $\mu \mathrm{mole}$ GE $\mathrm{g}^{-1} \mathrm{dw}$. The ratios of VCO: antioxidant $=2: 1,5: 1,10: 1$ and 15:1. $\mathrm{NH}=$ no heat treatment, $\mathrm{H}=$ heat treatment, ns $=$ not significant, ${ }^{*}=$ significant $(p<0.05)$. 
in coconut oil during the heating [38]. Moreover, RiceEvans et al., [42] addressed that $p$-hydroxycinnamic acid has relatively high antioxidant capacity because of its $\mathrm{CH}=\mathrm{CH}-\mathrm{COOH}$ group compared with gallic acid when heating was applied. Generally, cinnamic acid derivatives have been resonance stabilization more than benzoic acid derivatives [43] due to the greater delocalization of the unpaired electron of the antioxidant radical caused by the conjugated side chain. Furthermore, the electron-withdrawing properties of the carboxyl group attached to the aromatic ring have a negative influence on the hydrogen-donating abilities of hydroxybenzoic acids [44]. According to Seneviratne et al., [38] reported that the phenolic extracts of $\mathrm{COEH}$ were superior to that of COEC at all tested phenolic concentrations. This implied that the phenolic extracts of COEH display higher antioxidant capacities than those of COEC at any given total phenol concentration. This higher antioxidant capacity of the phenolic extracts of COEH should be associated with the more complex phenolic composition of COEH [38].

This result from Figures 4-6, ABTS scavenging activity of control seemed to be increased after heating might be due to induction radical of lauric acid and ABTS termination step of lipid oxidation.

\subsection{Effect of Thermal Processing on Lipid Oxidation of Lauric Acid with Added Tom-Kha Paste Extract and Test Antioxidants}

Lipid oxidation consists of primary oxidation (yielding lipid hydroperoxides, measured by PV and secondary oxidation the hydroperoxides from primary oxidation readily degrade yielding aldehydes, ketones, acids, esters, alcohols and short chain hydrocarbons, measured by TBARS and AV [45]. The results showed that PV of almost mixtures except LA-TK 2:1 and LA-T 15:1 was increased after heating (Figures 10-14). It pointed out that oxidation of lauric acid systems were pronounced by heating even the PV was quite low. Moreover, the result showed that all tested antioxidant could not prevent occurrence of hydroperoxides in the initiation step. It was possible that the concentration or solubility of the antioxidants may not enough to prevent oxidation of the mixtures. PV of non heated mixtures ranged from 0.99 to $3.35 \mathrm{meq} \cdot \mathrm{kg}^{-1}$ of lipid while heated mixtures ranged from 1.00 to 9.85 meq of active oxygen $\mathrm{kg}^{-1}$ of lipid. Form this result showed low peroxide value although the mixtures were treated by thermal processing due to lauric acid is saturated medium chain fatty acid which it has high resistance to rancidity [13]. And the stability of saturated fatty acids toward autoxidation decreased with increased chain length [46].
Before heating process at high concentration (at ratio of 2:1) of gallic acid, Trolox and Tom-Kha paste act as prooxidant in lauric acid system by determined by PV. However, after heat treatment, gallic acid, Trolox and $p$ hydroxycinnamic acid were prooxidant while Tom-Kha paste extract displayed good antioxidant property particularly increased of their concentrations. This may be due to thermal processing can improve solubility of polar antioxidant in non polar lipid system [38]. This result implied that antioxidant/prooxidant properties of tested antioxidants in lauric acid system depended on its concentration and heat treatment.

Combined effect of thermal processing and lauric acid on TBARS and AV of gallic acid (GA), $p$-hydroxycinnamic acid (HC), Trolox (T), Tom-Kha paste extract (TK) and control (absolute ethanol, E) showed in Figures 1014. The results showed that TBARS value of the mixtures was not significantly different $(p \geq 0.05)$ between before and after thermal processing. TBARS value of all the samples was less than $3 \mathrm{mg}$ MDA kg${ }^{-1}$ of lipid (0.27 $1.54 \mathrm{mg} \mathrm{MDA} \mathrm{kg}^{-1}$ ) which was classified as perfect material for human consumption (Huss, 1988). It indicated that all antioxidant samples used in lauric acid system were effective when applied with proper concentration. However, it was found that lauric acid was scarcely affected by oxidation at $150^{\circ} \mathrm{C}$ in the presence of $0.1 \%$ $\mathrm{KMnO}_{4}$.

AV represents mainly more non volatile products compared with volatile products of secondary oxidation [47]. The present result showed that antioxidant property of used antioxidants except gallic acid was concentration dependent. In similar study of Maurya and Devasagayam [48] who reported that hydroxycinnamic acid derivatives (ferulic and caffeic acids) have very good antioxidant potential at lower concentrations $(<5 \mu \mathrm{M})$ and start showing prooxidant behavior at higher concentrations. Interaction of phenolic compounds with free radical species in different phases provided diverse perspectives on their antioxidant/prooxidant properties [48].

\subsection{Effect of Thermal Processing on Lipid Oxidation of Virgin Coconut Oil with Added Tom-Kha Paste Extract and Tested Antioxidants}

Combined effect of virgin coconut oil (VCO) and thermal processing on PV, TBARS and AV of gallic acid, $p$ hydroxycinnamic acid, Trolox and Tom-Kha paste extract as well as the control showed in Figures 15-19. The results showed that $\mathrm{PV}$ of all virgin coconut oil mixtures ranged from 0.77 to 2.38 meq of active oxygen $\mathrm{kg}^{-1}$ of lipid. PV of the mixtures was not changed $(\mathrm{p} \geq 0.05)$ after heating. Additionally, it was found that PV of VCO was similar trend with lauric acid as antioxidants showed 


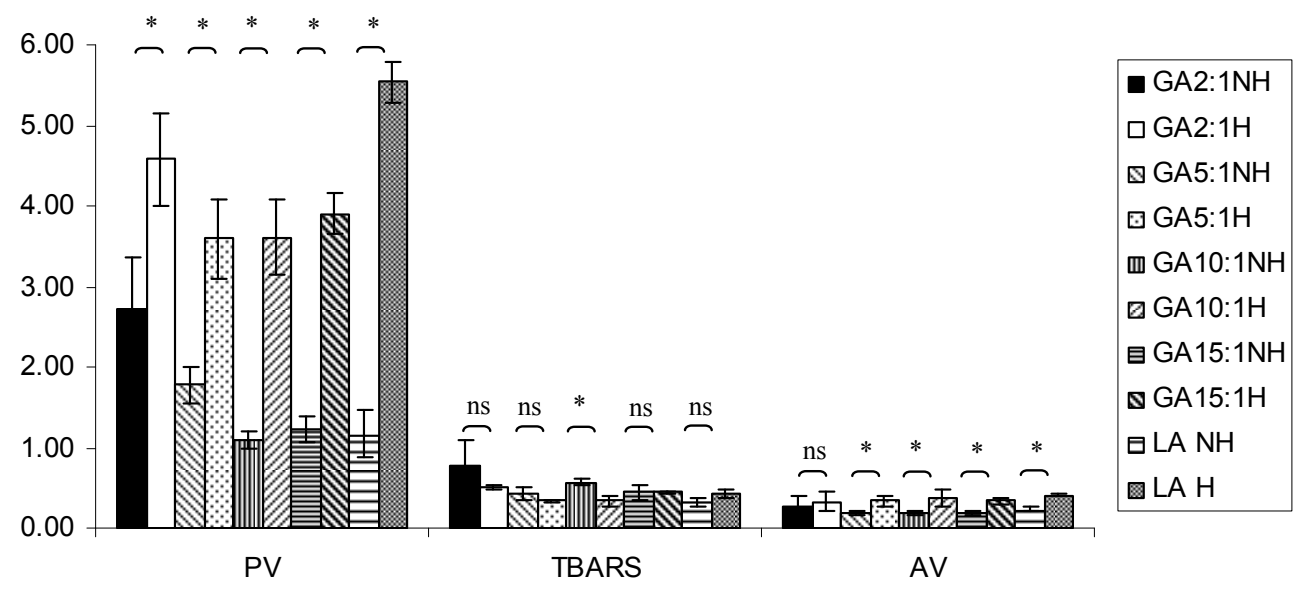

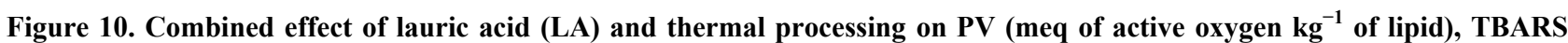
(mg MDA kg-1 of lipid) and AV of gallic acid (GA). The ratios of LA: GA = 2:1, 5:1, 10:1 and 15:1. NH=no heat treatment, $H$ $=$ heat treatment, $n s=$ not significant, ${ }^{*}=$ significant $(p<0.05)$.

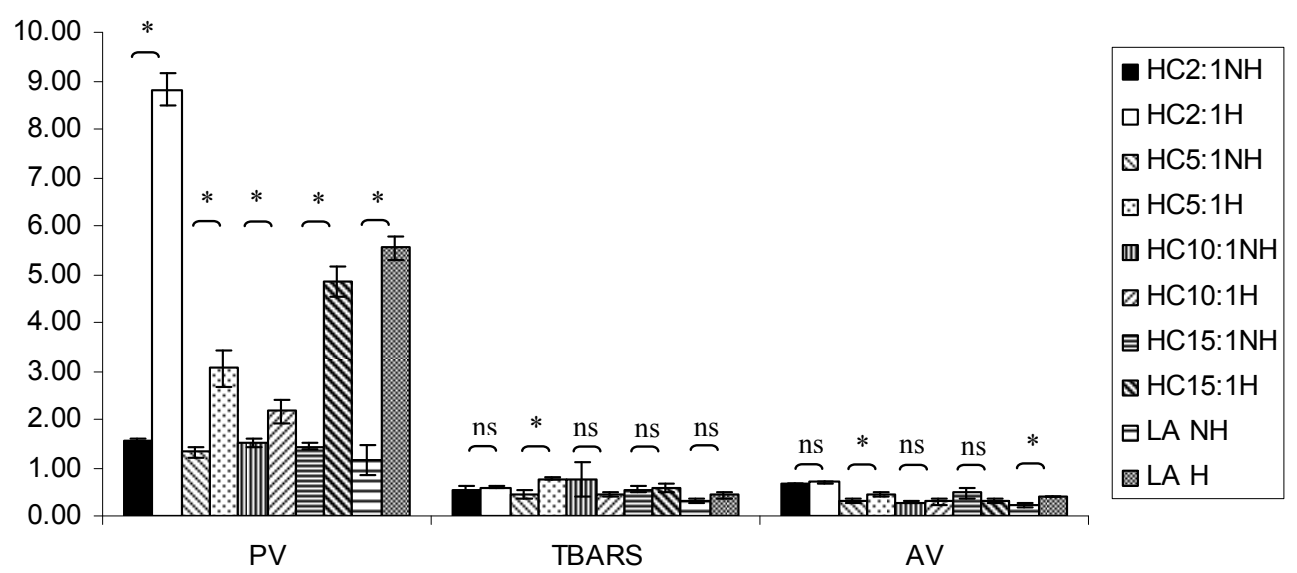

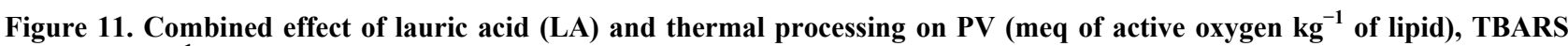

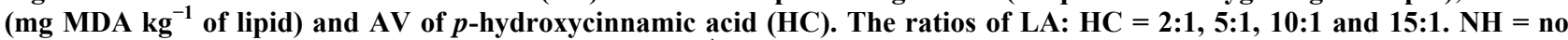
heat treatment, $\mathrm{H}=$ heat treatment, $\mathrm{ns}=$ not significant, ${ }^{*}=$ significant $(\mathrm{p}<0.05)$.

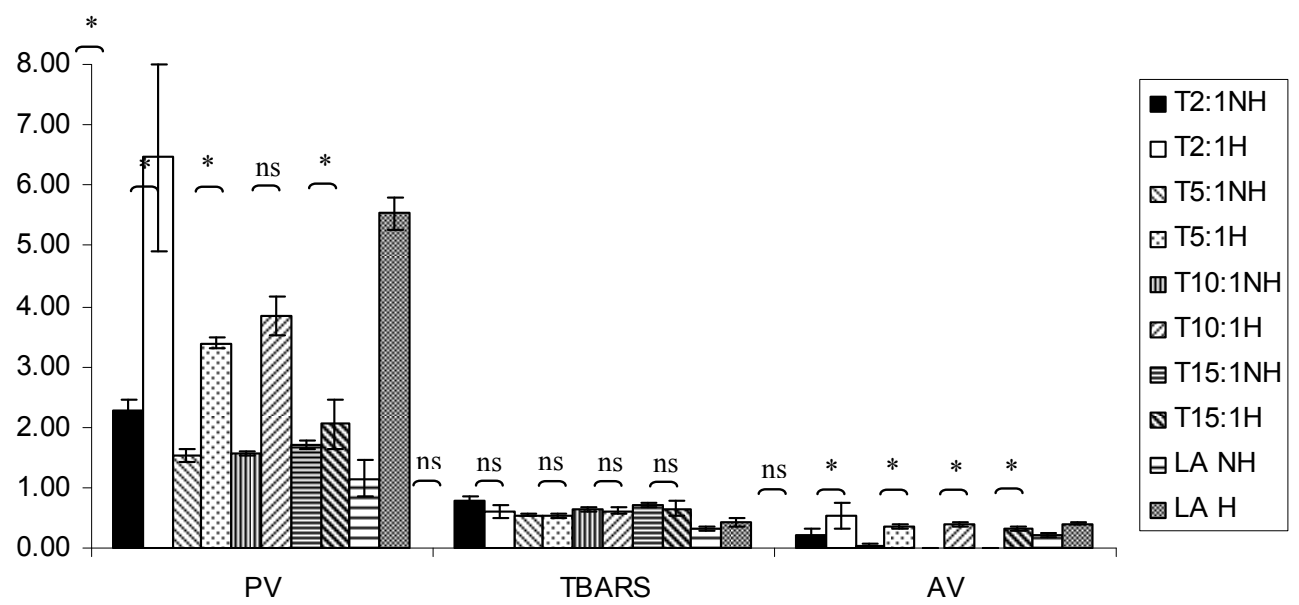

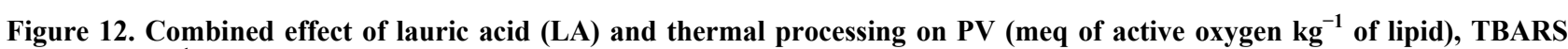
(mg MDA kg ${ }^{-1}$ of lipid) and AV of Trolox (T). The ratios of LA: T = 2:1, 5:1, 10:1 and 15:1. NH = no heat treatment, $H=$ heat

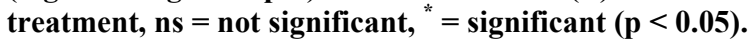




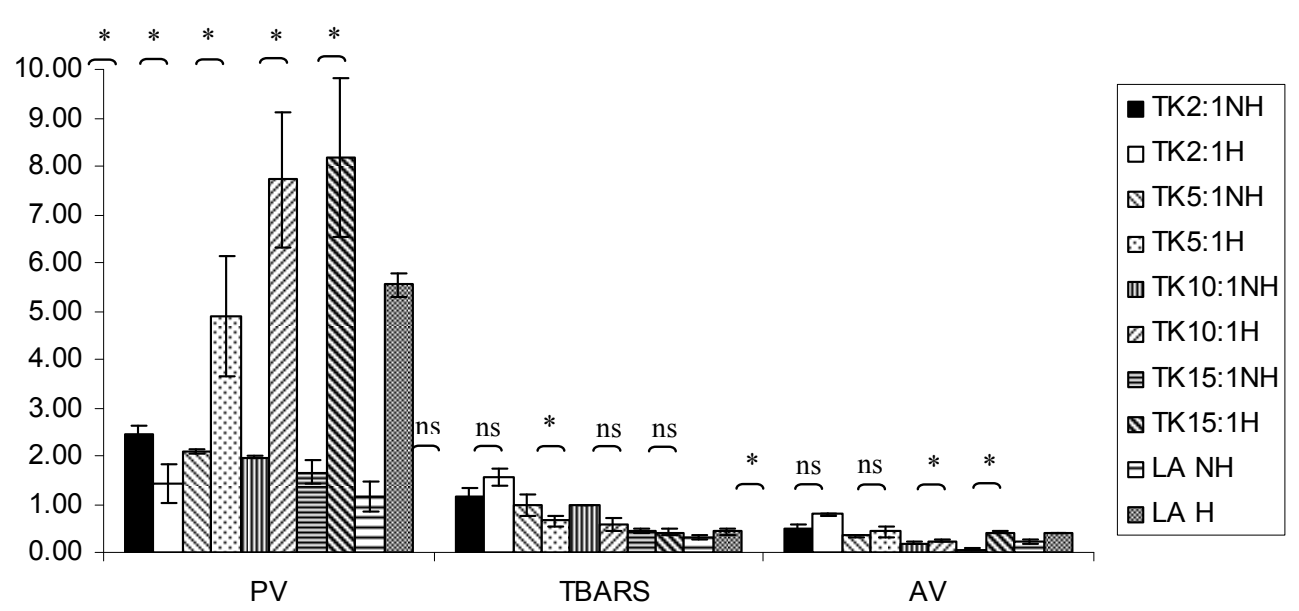

Figure 13. Combined effect of lauric acid (LA) and thermal processing on PV (meq of active oxygen $\mathrm{kg}^{-1}$ of lipid), TBARS (mg MDA kg-1 of lipid) and AV of Tom-Kha paste extract (TK). The ratios of LA: TK = 2:1, 5:1, 10:1 and 15:1. NH = no heat treatment, $\mathbf{H}=$ heat treatment, $\mathbf{n s}=$ not significant, ${ }^{*}=$ significant $(\mathbf{p}<0.05)$.

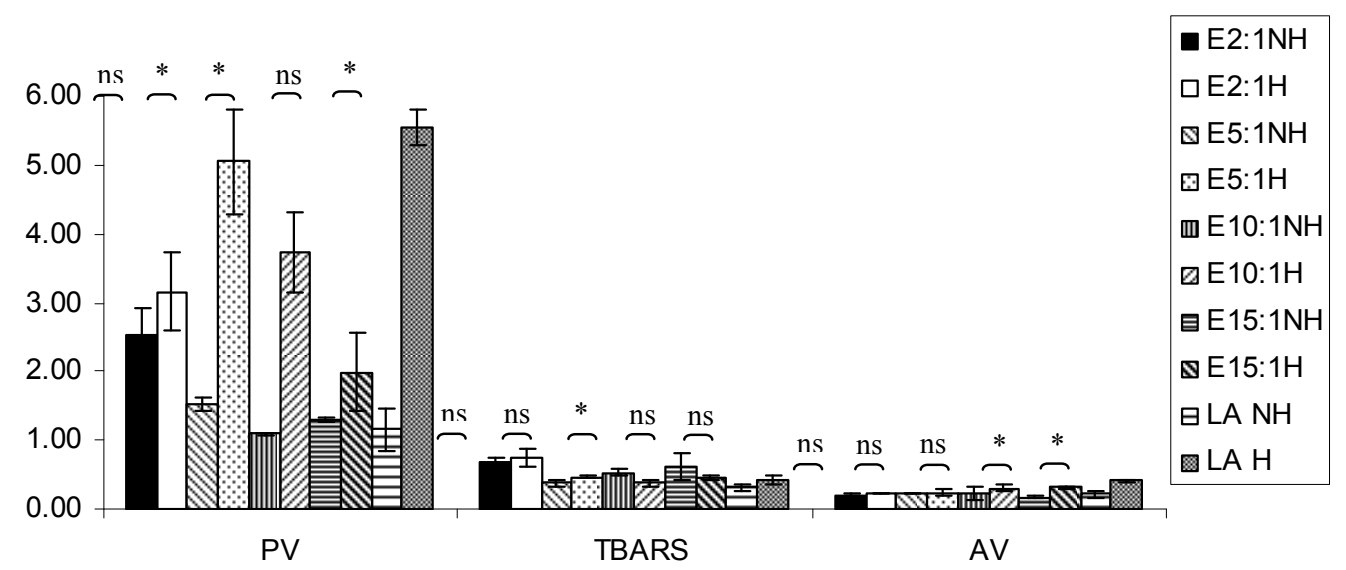

Figure 14. Effect of lauric acid (LA) and thermal processing on PV (meq of active oxygen $\mathrm{kg}^{-1}$ of lipid), TBARS (mg MDA

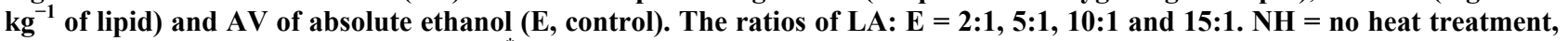
$\mathrm{H}=$ heat treatment, $\mathrm{ns}=$ not significant, ${ }^{*}=$ significant $(\mathrm{p}<0.05)$.

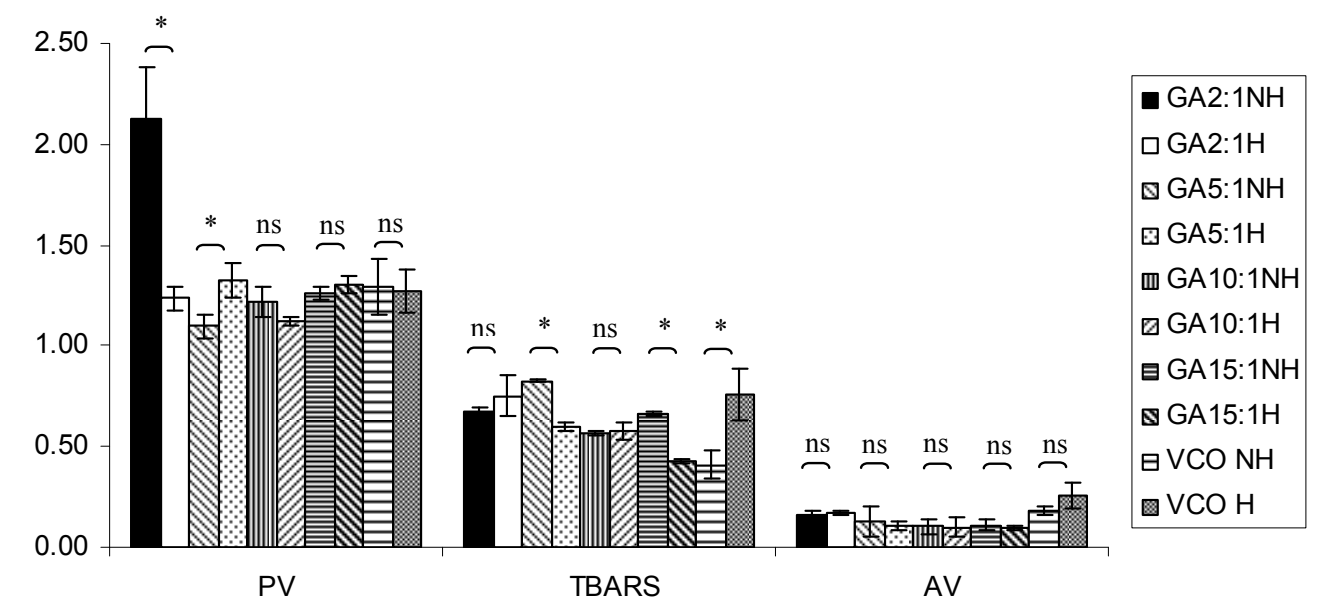

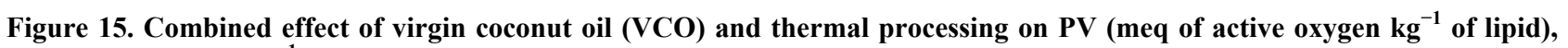
TBARS (mg MDA kg ${ }^{-1}$ of lipid) and AV of gallic acid (GA). The ratios of VCO: GA = 2:1, 5:1, 10:1 and 15:1. NH = no heat treatment, $H=$ heat treatment, $n s=$ not significant, ${ }^{*}=$ significant $(p<0.05)$. 


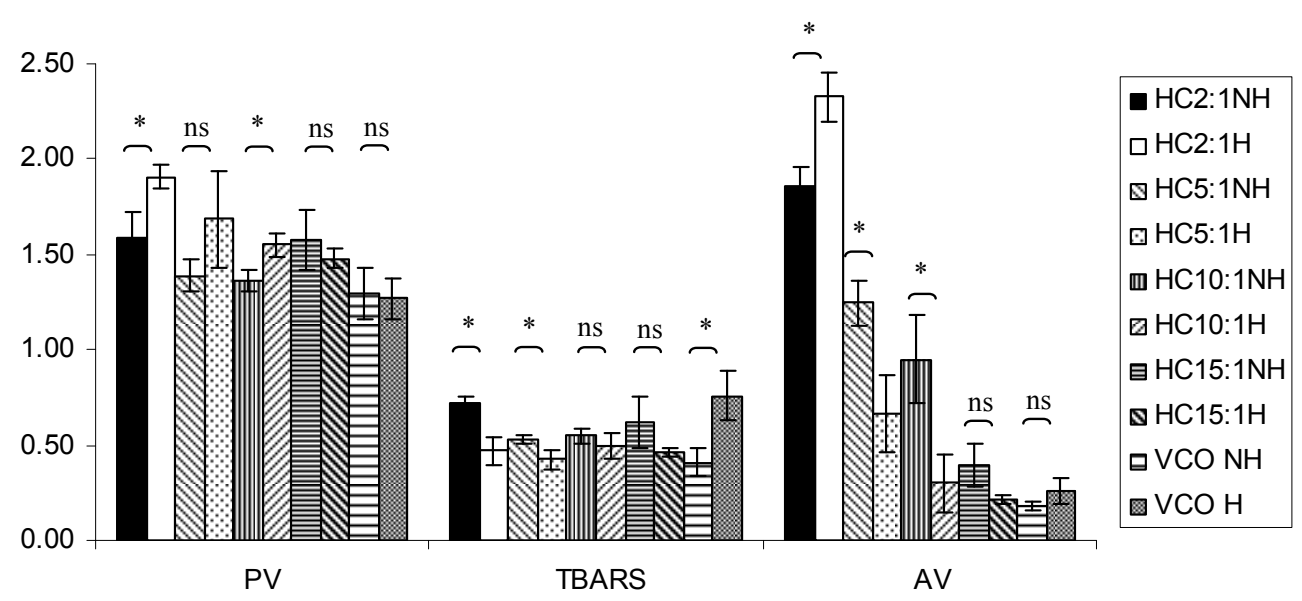

Figure 16. Combined effect of virgin coconut oil (VCO) and thermal processing on PV (meq of active oxygen $\mathrm{kg}^{-1}$ of lipid), TBARS (mg MDA kg ${ }^{-1}$ of lipid) and AV of $p$-hydroxycinnamic acid (HC). The ratios of VCO: HC = 2:1, 5:1, 10:1 and 15:1. $\mathrm{NH}=$ no heat treatment, $\mathrm{H}=$ heat treatment, $\mathrm{ns}=$ not significant, $*=$ significant $(\mathrm{p}<0.05)$.

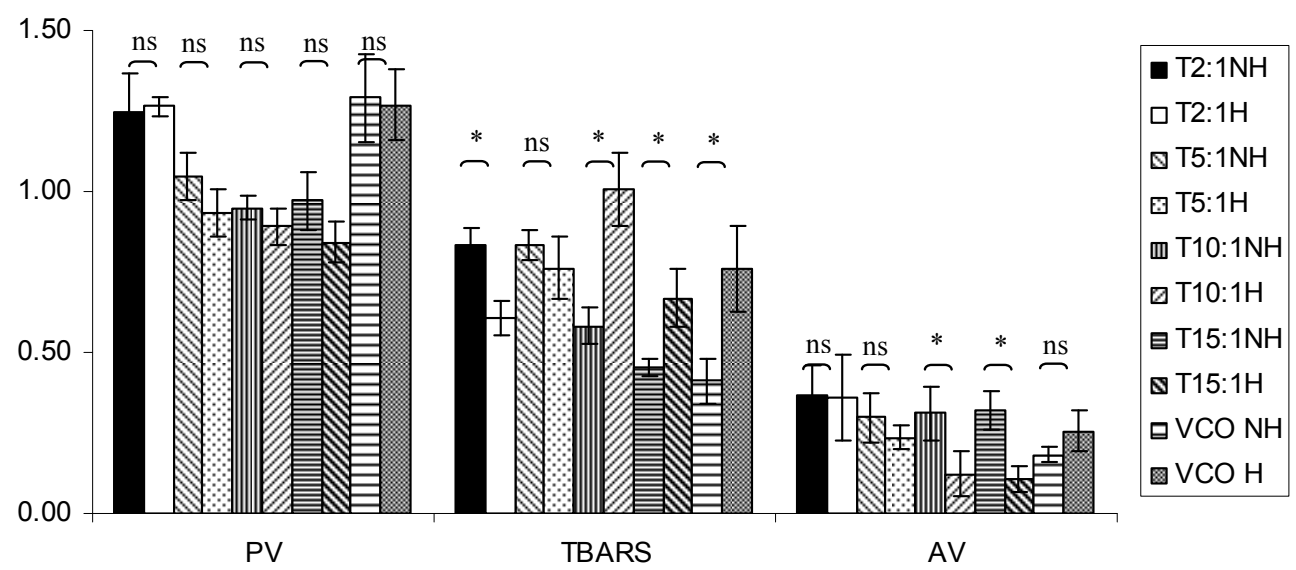

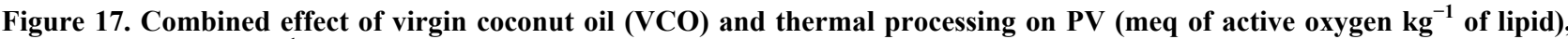
TBARS (mg MDA kg-1 of lipid) and AV of Trolox (T). The ratios of VCO: T = 2:1, 5:1, 10:1 and 15:1. NH = no heat treatment, $\mathbf{H}=$ heat treatment, $n s=$ not significant, ${ }^{*}=$ significant $(p<0.05)$.

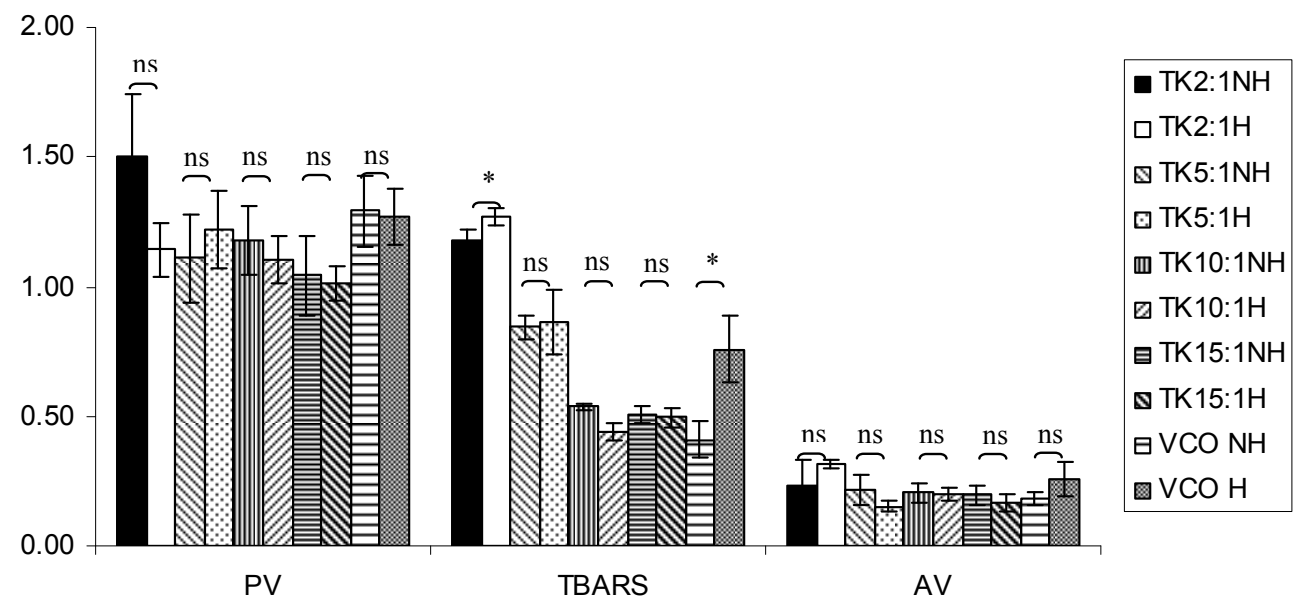

Figure 18. Combined effect of virgin coconut oil (VCO) and thermal processing on PV (meq of active oxygen $\mathrm{kg}^{-1}$ of lipid), TBARS (mg MDA kg-1 of lipid) and AV of Tom-Kha paste extract (TK). The ratios of VCO: TK = 2:1, 5:1, 10:1 and 15:1. $\mathrm{NH}=$ no heat treatment, $\mathrm{H}=$ heat treatment, $\mathrm{ns}=$ not significant, ${ }^{*}=$ significant $(\mathrm{p}<0.05)$. 


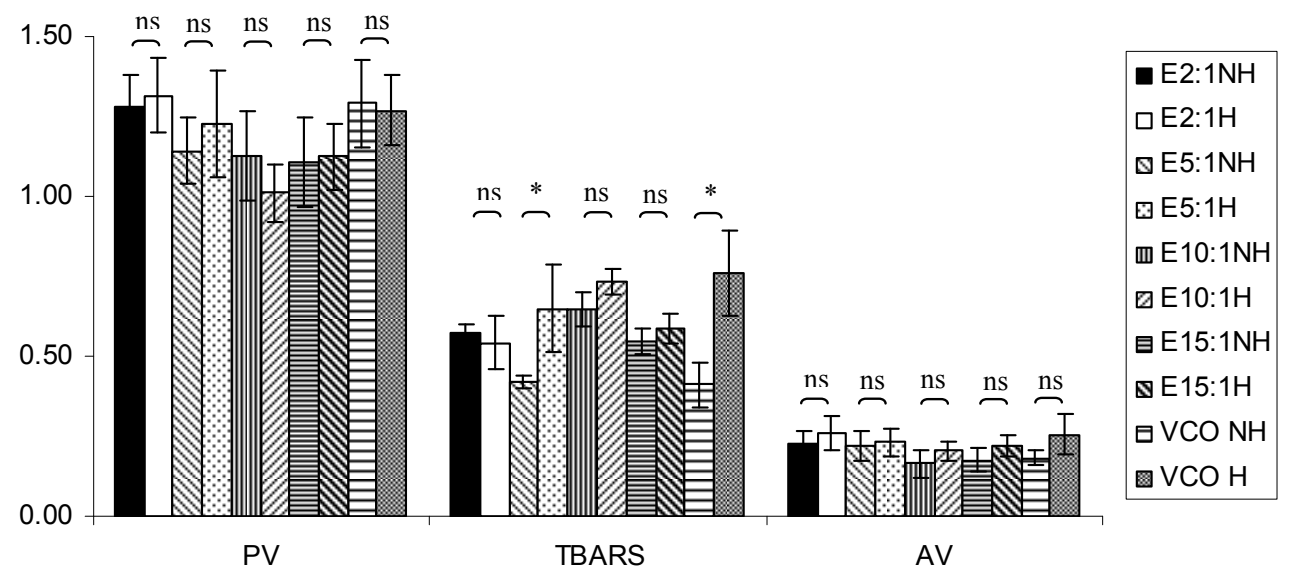

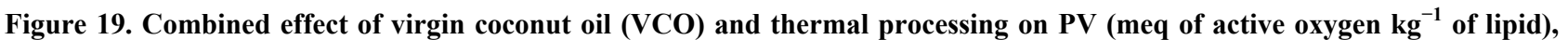
TBARS (mg MDA kg-1 of lipid) and AV of absolute ethanol (E, control). The ratios of VCO: E = 2:1, 5:1, 10:1 and 15:1. NH = no heat treatment, $\mathrm{H}=$ heat treatment, $\mathrm{ns}=$ not significant, ${ }^{*}=$ significant $(\mathrm{p}<0.05)$.

antioxidant potential at lower concentrations and given prooxidant activity at higher concentration.

TBARS of virgin coconut oil added with antioxidant samples seemed to be slightly increased after heating. After heat treatment, TBARS of virgin coconut oil without antioxidant (control) was increased from $0.41 \pm 0.07$ $\mathrm{mg} \mathrm{kg}{ }^{-1}$ to $0.76 \pm 0.13 \mathrm{mg} \mathrm{MDA} \mathrm{kg}$. In term of AV, virgin coconut oil with added gallic acid and Tom-Kha paste extract not changed by heat treatment while AV of virgin coconut oil with added $p$-hydroxycinnamic acid and Trolox seemed to decrease after heating. Using higher antioxidant concentration showed that TBARS value of all the mixtures had similar trend with PV. In addition, it was found that $\mathrm{AV}$ of all the mixtures except mixture of virgin coconut oil and $p$-hydroxycinnamic acid was not significantly changed $(p \geq 0.05)$ after heating. Although the lipid oxidation occurred during thermal processing, PV and TBARS value were under limited for human consumption at level of 8 meq of active oxygen $\mathrm{kg}^{-1}$ of lipid [49]. This may due to virgin coconut oil composed of high saturated fatty acid content ensured its stability against oxidative rancidity and thermal stability [50]. Many antioxidants could be made to exert prooxidant effects in vitro under certain conditions. This often involves their interaction with transition metal ions [48]. Therefore, it pointed out that antioxidant activity may depend on a number of many factors such as method assay, solvent type (polarity), plant type (bioactive compounds in term of quality and quantity as well as ratio of bioactive compounds) and system used or application as heated and non heated process, individual or mixed ingredients.

\section{Conclusion}

It can be summarized that gallic acid and Trolox were heat labile antioxidant while $p$-hydroxycinnamic acid and
Tom-Kha paste extract were heat stable antioxidant. Antioxidant activities of the mixture systems of lauric acid and antioxidants and thermal processing reduced DPPH scavenging activity of all treatments. A decrease of DPPH scavenging activity of all lauric acid-antioxidant mixtures was found after heat treatment. ABTS scavenging activity of the mixtures of lauric acid-gallic acid and lauric acid-Trolox were decreased while the mixtures of lauric acid-p-hydroxycinnamic acid and Tom-Kha paste extract were increased after heat treatment. The used antioxidants and Tom-Kha paste extract could prevent the propagation step of oxidation of lauric acid induced by heating. Antioxidant and/or prooxidant properties in lauric acid system depended on concentration and heating conditions. Tested antioxidants and Tom-Kha paste extract could inhibit oxidation of virgin coconut oil by thermal processing. Moreover, tested antioxidants and TomKha paste extract may possess antioxidant and/or prooxidant activities depended on method assay, concentration and type of tested antioxidant and lipid systems as well as heating. However, further research about antioxidant activities of Tom-Kha paste extract in vivo system to confirm bioavailability should be carried out.

\section{Acknowledgements}

This research was financial supported by Nutraceutical and Functional Food Research Center and Graduate School of Prince of Songkla University, Hat-Yai campus.

\section{REFERENCES}

[1] W. W. Nawar, "Lipid,” In: O. R. Fennema, Ed., Food Chemistry, 3rd Edition, Marcel Dekker, Inc., New York, 1996, pp. 210-243.

[2] R. A. Wheatley, "Some Recent Trends in the Analytical Chemistry of Lipid Peroxidation," TrAC, Trends in Ana- 
lytical Chemistry, Vol. 19, No. 10, 2000, pp. 617-628. doi:10.1016/S0165-9936(00)00010-8

[3] D. L. Madhavi, S. S. Deshpande and D. K. Salunkhe, "Food Antioxidants: Technological, Toxicological and Health Perspectives," Marcel Dekker, Inc., New York, 1996.

[4] Office of the National Culture Commission, "The Top Ten Thai Dishes Best Liked by Foreigners. Ministry of Foreign Affairs, Thailand (Online)," 2009. http://www.thaiwaysmagazine.com

[5] S. Siripongvutikorn, N. Pengseng, S. Ayusuk and W. Usawakesmanee, "Development of Green Curry Paste Marinade for White Shrimp (Litopenaeus vannamei). Songklanakarin," Journal of Science and Technology, Vol. 30, No. 1, 2008, pp. 35-40.

[6] S. Siripongvutikorn, P. Thummaratwasik and Y. Huang, "Antimicrobial and Antioxidation Effects of Thai Seasoning, Tom-Yum," LWT-Food Science and Technology, Vol. 38, No. 4, 2005, pp. 347-352.

[7] S. Siripongvutikorn, C. Thongraung, W. Usawakesmanee, T. Buatoom and P. Thummaratwasik, "Development of Instant Garcinia (Garcinia atroviridis) Tom-Yum Mix as a High Acid Seasoning," Journal of Food Processing and Preservation, Vol. 33, No. 1, 2009, pp. 74-86. doi:10.1111/j.1745-4549.2008.00238.x

[8] "Thai food to the World 2005. Thai Food Good Health Flash Multimedia. Ministry of Foreign Affairs, Thailand (Online)," 2009. http://www.thaifoodtoworld.com

[9] T. Juntachote, E. Berghofer, S. Siebenhandl and F. Bauer, "The Effect of Dried Galangal Powder and Its Ethanolic Extracts on Oxidative Stability in Cooked Ground Pork," Food Chemistry, Vol. 40, No. 2, 2007, pp. 324-330.

[10] T. Tachakittirungrod, S. Okonogi and S. Chowwanapoonpohn, "Study on Antioxidant Activity of Certain Plants in Thailand: Mechanism of Antioxidant Action of Guava Leaf Extract," Food Chemistry, Vol. 103, No. 2, 2007, pp. 381-388. doi:10.1016/j.foodchem.2006.07.034

[11] K. Nakahara, G. Trakoontivakorn, N. S. Ono. H. Alzoreky, M. Onishi-Kameyama and M. Yoshida, "Antimutagenicity of Some Edible Thai Plants, and a Bioactive Carbazole Alkaloid, Mahanine, Isolated from Micromelum minutum," Journal of Agricultural and Food Chemistry, Vol. 50, No. 17, 2002, pp. 4796-4802. doi:10.1021/jf025564w

[12] J. B. German and C. J. Dillard, "Saturated Fats: What Dietary Intake," American Journal of Clinical Nutrition, Vol. 80, No. 3, 2004, pp. 550-559.

[13] A. M. Marina, Y. B. Che Man, S. A. H. Nazimah and I. Amin, "Chemical Properties of Virgin Coconut Oil," Journal of the American Oil Chemists' Society, Vol. 86, No. 4, 2009, pp. 301-307.

[14] P. Siddhuraju and K. Becker, "The Antioxidant and Free Radical Scavenging Activities of Processed Cowpea (Vigna unguiculata (L.) Walp.) Seed Extracts," Food Chemistry, Vol. 101, No. 1, 2007, pp. 10-19. doi:10.1016/j.foodchem.2006.01.004

[15] R. Seah, S. Siripongvutikorn and W. Usawakesmanee, "Antioxidant and Antibacterial Properties in KeangHleung Paste and Its Ingredients," Asian Journal of Food and Agro-Industry, Vol. 3, No. 2, 2010, pp. 213-220.

[16] S. Ayusuk, S. Siripongvutikorn, P. Thummaratwasik and W. Usawakesmanee, "Effect of Heat Treatment on Antioxidant Properties of Tom-Kha Paste and Herbs/Spices Used in Tom-Kha Paste," Kasetsart Journal Natural Science, Vol. 43, No. 5, 2009, pp. 305-312.

[17] Y. Choi, S. M., Lee, J. Chun, H. B. Lee and J. Lee, "Influence of Heat Treatment on the Antioxidant Activities and Polyphenolic Compounds of Shiitake (Lentinus edodes) Mushroom," Food Chemistry, Vol. 99, No. 2, 2006, pp. 381-387. doi:10.1016/j.foodchem.2005.08.004

[18] S. Y. Kim, S. M. Jeong, W. P. Park, K. C. Nam, D. U. Ahn and S. C. Lee, "Effect of Heating Conditions of Grape Seeds on the Antioxidant Activity of Grape Seed Extracts," Food Chemistry, Vol. 97, No. 3, 2006, pp. 472479. doi:10.1016/j.foodchem.2005.05.027

[19] F. J. Morales and M.-B. Babel, "Antiradical Efficiency of Maillard Reaction Mixtures in a Hydrophilicmedia," Journal of Agricultural and Food Chemistry, Vol. 50, No. 10, 2002, pp. 2788-2792. doi:10.1021/if011449u

[20] G. C. Yen and G. L. Hsieh, "Antioxidant Effects on Dopamine and Relate Compound," Bioscience, Biotechnology, and Biochemistry, Vol. 60, No. 3, 1997, pp. 1646 1649. doi:10.1271/bbb.61.1646

[21] R. Re, N. Pellegrini, A. Proteggente, A. Pannala, M. Yang and C. Rice-Evans, "Antioxidant Activity Appliyin an Improved ABTS Radical Cation Decolorization Assay," Free Radical Biology and Medicine, Vol. 26, No. 9-10, 1999, pp. 1231-1237.

[22] C. Paquot, "Standard Methods for the Analysis of Oils, Fats and Derivatives," 6th Edition, Pergamon Press, New York, 1979 .

[23] J. A. Buege and S. D. Aust, "Microsomal Lipid Peroxidation," In: S. Flesicher and L. Packer, Eds., Methods in Enzymology, Academic Press, New-York, pp. 302-310.

[24] R. Prior, X. Wu and K. Schaich, "Standardized Methods for the Determination of Antioxidant Capacity and Phenolics in Foods and Dietary Supplements," Journal of Agricultural and Food Chemistry, Vol. 53, No. 10, 2005, pp. 4290-4302. doi:10.1021/jf0502698

[25] J. M. Awika, L. W. Rooney, X. Wu, R. L. Prior and L. Cisneros-Zevallos, "Screening Methods to Measure Antioxidant Activity of Sorghum (Sorghum bicolor) and Sorghum Products," Journal of Agricultural and Food Chemistry, Vol. 51, No. 23, 2003, pp. 6657-6662. doi:10.1021/jf034790i

[26] G. C. Yen and C. Y. Hung, "Effects of Alkaline and Heat Treatment on Antioxidative Activityand Total Phenolics of Extracts from Hsian-tsao (Mesona procumbens Hemsl.)," Food Research International, Vol. 33, No. 6, 2000, pp. 487-492. doi:10.1016/S0963-9969(00)00073-9

[27] J. C. Chen, J. Y. Yeh, P. C. Chen and C. K. Hsu, "Phenolic Content and DPPH Radical Scavenging Activity of Yam-Containing Surimi Gels Influenced by Salt and Heating," Asian Journal of Health and Information Sciences, Vol. 2, No. 1-4, 2007, pp. 1-11.

[28] R. Arabshahi-D, V. Devi and A. Urooj, "Evaluation of 
Antioxidant Activity of Some Plant Extracts and Their Heat, $\mathrm{pH}$ and Storage Stability," Food Chemistry, Vol. 100, No. 3, 2007, pp. 1100-1105. doi:10.1016/j.foodchem.2005.11.014

[29] M. Murcia, A. M. Jiménez and M. Martínez-Tomé, "Vegetables Antioxidant Losses during Industrial Processing and Refrigerated Storage," Food Research International, Vol. 42, No. 8, 2009, pp. 1046-1052. doi:10.1016/j.foodres.2009.04.012

[30] M. C. Nicoli, M. Anese and M. Parpinel, "Influence of Processing on Antioxidant Properties of Fruit and Vegetables," Trends in Food Science and Technology, Vol. 10, No. 3, 1999, pp. 94-100. doi:10.1016/S0924-2244(99)00023-0

[31] G. Gazzani, A Papetti, G. Massolini and M. Daglia, "Anti- and Pro-Oxidant Activity of Water Soluble Components of Some Common Diet Vegetables and the Effect of Thermal Treatment," Journal of Agricultural and Food Chemistry, Vol. 46, No. 10, 1998, pp. 4118-4122. doi:10.1021/jf980300o

[32] S. T. Talcott, L. R. Howard and C. H. Brenes, "Antioxidant Changes and Sensory Properties of Carrot Puree Processed with or without Periderm Tissue," Journal of Agricultural and Food Chemistry, Vol. 48, No. 4, 2000, pp. 1315-1321. doi:10.1021/jf9910178

[33] R. Seah, S. Siripongvutikorn and W. Usawakesmanee, "Stability of Antioxidant and Antibacterial Properties in Heated Turmeric-Chili Paste and Its Ingredients," International Food Research Journal, Vol. 18, No. 4, 2011, pp. 397-404.

[34] T. Juntachote and E. Berghofer, "Antioxidative Properties and Stability of Ethanolic Extracts of Holy Basil and Galangal," Food Chemistry, Vol. 92, No. 2, 2005, pp. 193202. doi:10.1016/i.foodchem.2004.04.044

[35] Z. Rehman, A. Salariya and F. Habib, "Antioxidant Activity of Ginger Extract in Sunflower Oil," Journal of the Science of Food and Agriculture, Vol. 83, No. 7, 2003, pp. 624-629. doi:10.1002/jsfa.1318

[36] G. Xu, X. Ye, J. Chen and D. Liu, "Effect of Heat Treatment on the Phenolic Compound and Antioxidant Capacity of Citrus Peel Extract," Journal of Agricultural and Food Chemistry, Vol. 55, No. 2, 2007, pp. 330-335. doi:10.1021/jf0625171

[37] S. Shobana and K. A. Naidu, "Antioxidant Activity of Selected Indian Spices," Prostaglandins Leukotrienes and Essential Fatty Acids, Vol. 62, No. 2, 2000, pp. 107-110. doi:10.1054/plef.1999.0128

[38] K. N. Seneviratne, C. D. Hapuarachchl and S. Ekanayake, "Comparison of the Phenolic-Dependent Antioxidant Properties of Coconut Oil Extracted under Cold and Hot Conditions," Food Chemistry, Vol. 114, No. 4, 2009, pp. 1444-1449. doi:10.1016/j.foodchem.2008.11.038
[39] A. M. Marina, Y. B. Che Man and I. Amin, "Virgin Coconut Oil: Emerging Functional Food Oil," Trends in Food Science and Technology, Vol. 20, No. 10, 2009, pp. 481-487. doi:10.1016/i.tifs.2009.06.003

[40] F. J. Weber and J. A. M. de Bont, "Adaptation Mechanisms of Microorganisms to the Toxic Effects of Organic Solvents on Membranes," Biochimica et Biophysica Acta, Vol. 1286, No. 3, 1996, pp. 225-245. doi:10.1016/S0304-4157(96)00010-X

[41] G.-C. Yen, P.-D. Duh and H.-L. Tsai, "Antioxidant and Pro-Oxidant Properties of Ascorbic Acid and Gallic Acid," Food Chemistry, Vol. 79, No. 3, 2002, pp. $307-$ 313. doi:10.1016/S0308-8146(02)00145-0

[42] C. Rice-Evans, N. J. Miller and G. Paganga, "StructureAntioxidant Activity Relationships of Flavonoids and Phenolic Acids," Free Radical Biology and Medicine, Vol. 20, No. 7, 1996, pp. 933-956. doi:10.1016/0891-5849(95)02227-9

[43] F. Shahidi and M. Naczk, "Phenolics in Food and Nutraceuticals," CRC Press, New York, 2004.

[44] S. S. Pekkarinen, H. S. Heiko Stöckmann, K. Schwarz, M. Heinonen and A. I. Hopia, "Antioxidant Activity and Partitioning of Phenolic Acids in Bulk and Emulsified Methyl Linoleate," Journal of Agricultural and Food Chemistry, Vol. 47, No. 8, 1999, pp. 3036-3043. doi:10.1021/jf9813236

[45] E. Choe and D. B. Min, "Mechanisms and Factors for Edible Oil Oxidation," Comprehensive Reviews in Food Science and Food Safety, Vol. 5, No. 4, 2006, pp. 169186. doi:10.1111/j.1541-4337.2006.00009.x

[46] M. H. Brodnitz, "Autoxidation of Saturated Fatty Acids," Journal of Agricultural and Food Chemistry, Vol. 16, No. 6, 1968, pp. 994-999. doi:10.1021/jf60160a001

[47] M. Gordon, "The Development of Oxidative Rancidity in Foods," In: J. Pokony, N. Yanishlieva and M. Gordon, Eds., Anioxidants in Food: Practical Applications, CRC Press, New York, 2001, pp. 7-21.

[48] D. K. Maurya and T. P. Devasagayam, "Antioxidant and Prooxidant Nature of Hydroxycinnamic Acid Derivatives Ferulic and Caffeic Acids," Food and Chemical Toxicology, Vol. 48, No. 12, 2010, pp. 3369-3373. doi:10.1016/i.fct.2010.09.006

[49] H. H. Huss, "Fresh Fish-Quality and Quality Changes: A Training Manual Prepared for the FAO/DANIDA Training Programme on Fish Technology and Quality Control," FAO, Rome, 1988.

[50] N. H. Jayadas and K. P. Nair, "Coconut Oil as Base Oil for Industrial Lubricants-Evaluation and Modification of Thermal, Oxidative and Low Temperature Properties," Tribology International, Vol. 39, No. 9, 2006, pp. 873878. doi:10.1016/j.triboint.2005.06.006 